\title{
Root-soil mechanical interactions during pullout and failure of root bundles
}

\author{
M. Schwarz, ${ }^{1,2}$ D. Cohen, ${ }^{2}$ and D. Or ${ }^{2}$ \\ Received 18 November 2009; revised 29 June 2010; accepted 4 August 2010; published 21 December 2010.
}

[1] Roots play a major role in reinforcing and stabilizing steep hillslopes. Most studies in slope stability implement root reinforcement as an apparent cohesion by upscaling the behavior of static individual roots. Recent studies, however, have shown that much better predictions of slope stability can be made if the progressive failure of bundles of roots are considered. The characteristics of progressive failure depend on interactions between soil deformation and root bundle geometric and mechanical properties. We present a detailed model for the quantitative description of the mechanical behavior of a bundle of roots under strain-controlled mechanical forcing. The Root Bundle Model explicitly considers typical values of root-size spatial distribution (number and dimension of roots), geometric factors (diameter-length proportion, tortuosity, and branching characteristics), and mechanical characteristics (tensile strength and Young's modulus) and interactions under various soil conditions (soil type, confining pressure, and soil moisture). We provide systematic analyses of the roles of these factors on the mechanical response of the bundle and explore the relative importance of various parameters to the macroscopic root-soil mechanical response. We distinguish between increased strength imparted by small roots at small deformations and the resilience imparted by larger roots to the growth of large tensile cracks, showing that the maximal reinforcement of fine roots is reached within the first $5 \mathrm{~cm}$ of displacement whereas a root of $20 \mathrm{~mm}$ diameter may reach its maximal pullout force after $10 \mathrm{~cm}$ displacement. The model reproduces the gradual straining and ultimate residual failure behavior of root systems often observed in hillslopes, with progressive growth of tension cracks improving estimations of root reinforcement when considering the effects of root distribution and the variation of the pullout force as a function of displacement. These results enhance understanding of root reinforcement mechanisms and enable more realistic implementation of root reinforcement modeling for stability calculations of vegetated slopes and for guiding ongoing experimental efforts to gather critical root-soil mechanical information.

Citation: Schwarz, M., D. Cohen, and D. Or (2010), Root-soil mechanical interactions during pullout and failure of root bundles, J. Geophys. Res., 115, F04035, doi:10.1029/2009JF001603.

\section{Introduction}

[2] Roots fulfill a diverse array of functions in plant life ranging from capture and transport of subsurface resources, to mechanical anchoring and stabilizing of trees in support of growth, and to resilience to external stresses such as wind, snow accumulation, rock impact, and soil creep [Coutts, 1983; Schmidt et al., 2001; Rickli, 2001; Casadei and Dietrich, 2003; Johnsson et al., 2006]. Roots also stabilize soil on steep slopes by virtue of their extensive proliferation and mechanical properties. Additionally, plant water uptake by roots decreases soil moisture, thereby

\footnotetext{
${ }^{1}$ Swiss Federal Institute for Forest, Snow and Landscape Research, Birmensdorf, Switzerland.

${ }^{2}$ Soil and Terrestrial Environmental Physics, Institute of Terrestrial Ecosystems, ETH Zurich, Zurich, Switzerland.

Copyright 2010 by the American Geophysical Union. 0148-0227/10/2009JF001603
}

increasing matric suction and mechanical strength. Often, these disparate mechanical effects have been lumped into an apparent increase in soil cohesion as defined in Mohr Coulomb analysis [Genet et al., 2008].

[3] The processes by which roots stabilize slopes depend to a large extent on their size, spatial distribution, and geometry (diameter-length proportion, tortuosity, and branching characteristics). In some cases roots stabilize a slope by bridging across preexisting weak zones and basal shear planes, and thus become loaded during failures of these zones [Schwarz et al., 2010]. For shallow and laterally extensive root networks, slope stability may increase when sufficient roots cross potential tension cracks (scarp) that define the perimeter of a shallow landslide [Schwarz et al., 2009].

[4] Various methods to quantify effects of root reinforcement along a landslide shear plane have been proposed [e.g., Wu et al., 1979; Ekanayake and Phillips, 1999; Pollen, 2008]. Wu et al.'s [1979] approach is widely used as it 
incorporates data on root and soil mechanical properties in an easy-to-apply model. A limiting assumption in $W u$ et al.'s [1979] model is that all roots break simultaneously which is not supported by observations [Pollen et al., 2004; $W u, 2007$; Fan and Su, 2008] and results in a consistent overprediction of actual root reinforcement function. Early models typically did not consider geometrical and stressstrain behavior of root bundles, a necessary element for describing complex interactions between roots and soil matrix. They also overlooked the function of roots of different sizes in reinforcement as discussed in a recent review by Schwarz et al. [2009]. These root size and geometrical characteristics determine how root reinforcement is progressively activated during gradual loading and soil deformation.

[5] Recently, concepts of fiber bundle models (FBM) have been applied to root reinforcement and bank stability problems [Pollen et al., 2004; Pollen, 2008; Mickovski et al., 2009; Hallett et al., 2009]. The classical FBM model assumes an incremental stress loading in which an imposed tensile force is distributed across unbroken fibers. When a root or fiber breaks, its load is redistributed over the remaining fibers. During each load step, force is redistributed until either equilibrium is reached or the entire bundle fails. Fiber bundle models show better fit to experimental data [Pollen et al., 2004; Pollen, 2008; Mickovski et al., 2009] and rely on simple power law relationships between root size and mechanical behaviors. However, details of root-soil interactions and root failure mechanisms such as root stretching, size-stiffness relationship, and rootsoil friction, which control whether roots slip or fail, are not included. In particular, existing models do not consider the mechanical properties of soil in a consistent way. Present fiber bundle models also do not include models for the estimation of the root size distribution where geometric and mechanical properties vary with root size. Moreover, root reinforcement models are typically not tuned to study lateral reinforcement (with the notable exception of Schmidt et al. [2001]).

[6] The mechanical behavior of pulled roots depends on numerous parameters (detailed below). Previous studies [e.g., Waldron and Dakessian, 1981; Commandeur and Pyles, 1991; Dupuy et al., 2005; Mickovski et al., 2007; Fan and $\mathrm{Su}, 2008$ ] provide a basis for identifying first-order control variables that must be included in any rootreinforcement model. One such class of variables is related to root geometry, which is notoriously difficult to characterize precisely [Danjon and Reubens, 2008], and only a few studies describe how the various geometrical features of roots (e.g., variation of diameter with length, branching points, tortuosity) contribute to the mechanical behavior of individual roots [Dupuy et al., 2005; Mickovski et al., 2009]. Most research has focused primarily on individual variables such as root diameter or branching pattern [e.g., Stokes et al., 1996; Dupuy et al., 2005; Mickovski et al., 2007]. For example, recent studies have shown the importance of branching points on the stress-strain behavior of pulled roots [Dupuy et al., 2005; Mickovski et al., 2007].

[7] An additional set of key variables is related to the intrinsic mechanical properties of individual roots and bundles. A common measure of root reinforcement is the maximum tensile strength of a root which primarily depends on root diameter. Root stiffness (Young's modulus) is also known to depend on root diameter [Operstein and Frydman, 2000; Tosi, 2007; Fan and Su, 2008]. Consequently, stiffer roots mobilize more stress than less stiff roots for the same amount of strain. Commandeur and Pyles [1991] showed that root tortuosity is also an important parameter influencing the macroscopic elastic behavior of a pulled root. Tortuosity should therefore induce an apparent Young's modulus smaller than the root's intrinsic Young's modulus due to frictional interactions between the root and the surrounding soil as the root reconfigures during pulling. Friction at the root-soil interface is usually considered constant and frictional forces are calculated assuming a constant root diameter [Waldron and Dakessian, 1981; Ennos, 1990]. In reality, root diameter decreases along the root axis, and the activation of root-soil friction depends on the pullout force. Moreover, root-soil friction changes considerably during stretching and slippage but this aspect is neglected.

[8] The primary objective of this study was to quantify the effects of various root geometrical and mechanical parameters on the tensile strength of an individual root and on the mechanical behavior of a bundle of roots under pullout tests. We included the effects of root length, root diameter and its variation along the root, maximum tensile strength, Young's modulus, root-soil interfacial friction, branchingpoint frequency, and root tortuosity into a numerical fiber bundle model that describes the mechanical dynamic pullout behavior of roots embedded in a soil matrix during straincontrolled deformation. The model strikes a compromise between complexity arising from root-soil interactions and oversimplifications of previous models by judicious selection of a minimum number of parameters needed to describe key features of the geometry and mechanics of pulled roots.

[9] The specific objectives of this study are therefore to (1) present a new model (termed the Root Bundle Model or RBM) for the calculation of the force-displacement relation for an individual root, (2) analyze the pullout behavior of a bundle of roots during strain loading, and (3) analyze root reinforcement characteristics of a bundle of roots for different root-size distributions and under various soil conditions.

[10] The model considers how a bundle of lateral roots of different diameters contributes to the global reinforcement at different strain increments during the failure of a shallow landslide. Only root sections away from the tree stem are used in the calculations, with the pullout direction away from the root tip (Figure 1). The model is built on a hierarchy of submodels [Schwarz et al., 2010]. In the following sections we present first a detailed description of the geometry and mechanics of individual roots (section 2), then we explain how geometry and mechanics of individual roots are implemented in a model that computes the pullout behavior (force displacement) (section 3). Finally, we combine a root frequency-size distribution model with the pullout model of individual root to obtain a strain-controlled pullout model of a bundle of roots that includes the effects of root elongation, root-soil friction, and root failure (section 4).

\section{Geometrical and Mechanical Description of Individual Roots}

[11] Experimental pullout tests on individual roots embedded in a soil matrix show that following initial (elastic) root stretching, roots may then either slip out or 


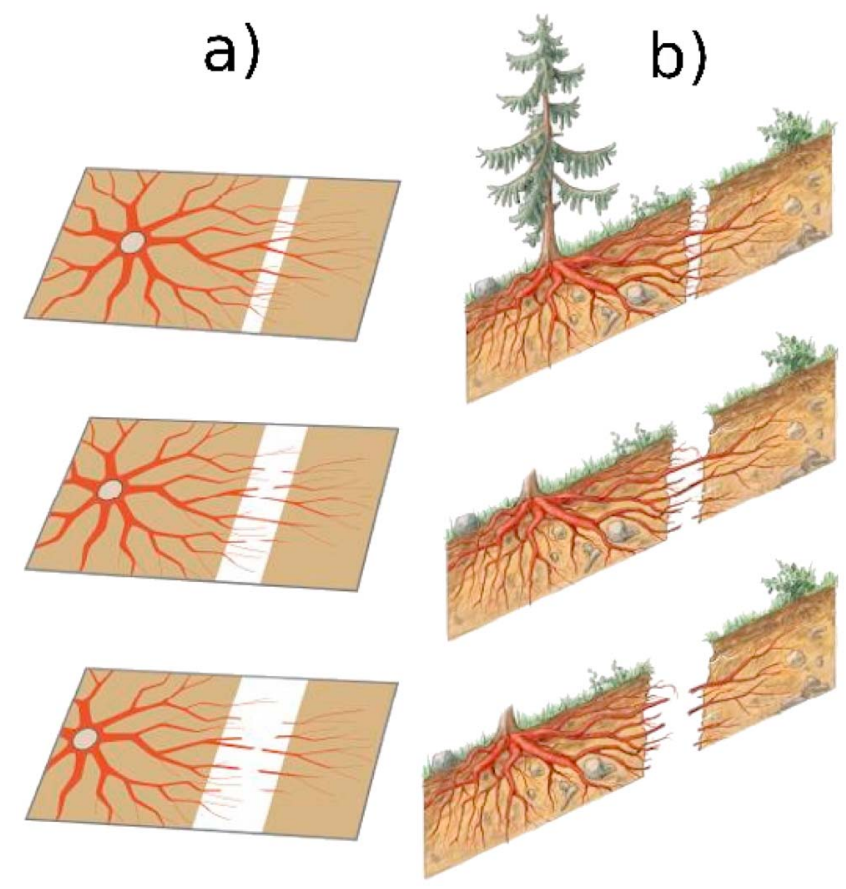

Figure 1. Illustration of a pulled bundle of roots modeled by the RBM at three stages of deformation from (a) plane and (b) cross-sectional views. The RBM considers root bundle uphill of the transverse failure plane.

simply fail and break [Norris, 2005]. Figure 2 shows these different responses on a schematic force-displacement diagram. The first part of the pullout curve is dominated by the elastic properties of root and soil. The nonlinear behavior that follows is documented experimentally [Hamza et al., 2007; Mickovski et al., 2007] and is due to the progressive activation of root-soil interfacial friction (details of this effect are described later). The maximum pullout force is reached when either the maximum (intrinsic) tensile strength of the root is exceeded (Figure 2, light gray dashed line), or when root-soil friction drops, reducing the pullout force, and the root slips out (Figure 2, dark gray dashed line). Once broken, a root carries no load. During slip, the pullout curve may display complex behavior resulting from interactions between root strength, root elongation, and root-soil friction.

\subsection{Individual Root Geometry}

[12] Single root geometry is characterized by a lengthdiameter relationship, branching points, and tortuosity. Various empirical relationships [e.g., Wu et al., 1988; Pollen, 2008] have been proposed for characterizing root length as a function of root diameter (Figure 3). Here we use the relation

$$
L=L_{0} d^{g},
$$

where $L$ is the length of the root in mm following its axis, $L_{0}$ and $g$ are empirical coefficients, and $d$ is the root diameter in millimeters measured where the root is pulled (this corresponds to $d_{n}$, see equation (5) and Figure 4). In subsequent calculations, unless noted otherwise, we use

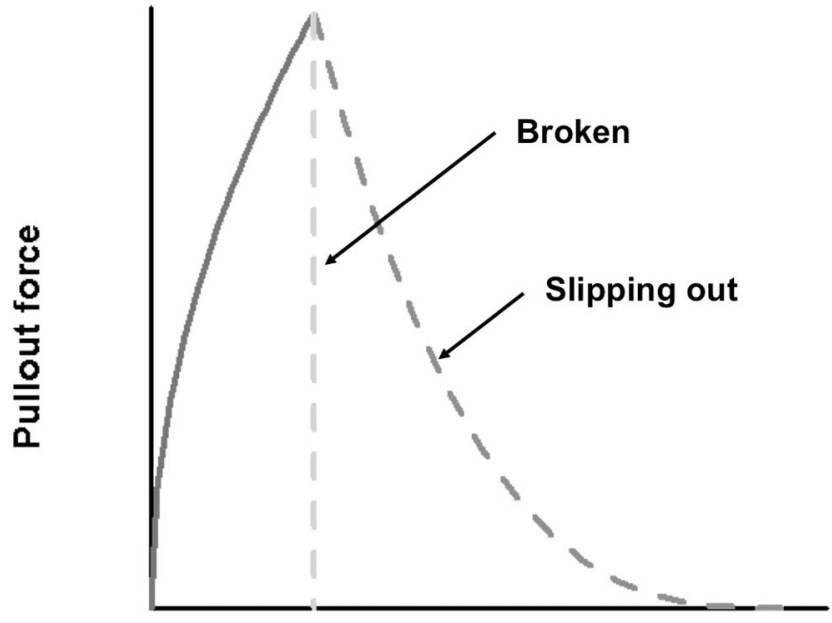

\section{Displacement}

Figure 2. Pullout curves of an individual root on a forcestrain diagram. The initial elastic stretch of a root (solid line) may be followed by gradual slip out (dark gray dashed line) or abrupt failure and breakage (vertical light gray dashed line) [Waldron and Dakessian, 1981].

$g=0.63$ and $L_{0}=335$, values that fit data of twenty seven secondary lateral roots of spruce (Picea abies L.) collected in a forest stand near Zurich, Switzerland (see Vanomsen [2006] for description of field site). Roots were sampled from the first $400 \mathrm{~mm}$ of the topsoil layer and were hand washed gently under water to remove residual soil and root hairs. For each root, we measured root diameter at its base, tortuous and straight root length, diameter at each branching points, and branching distances.

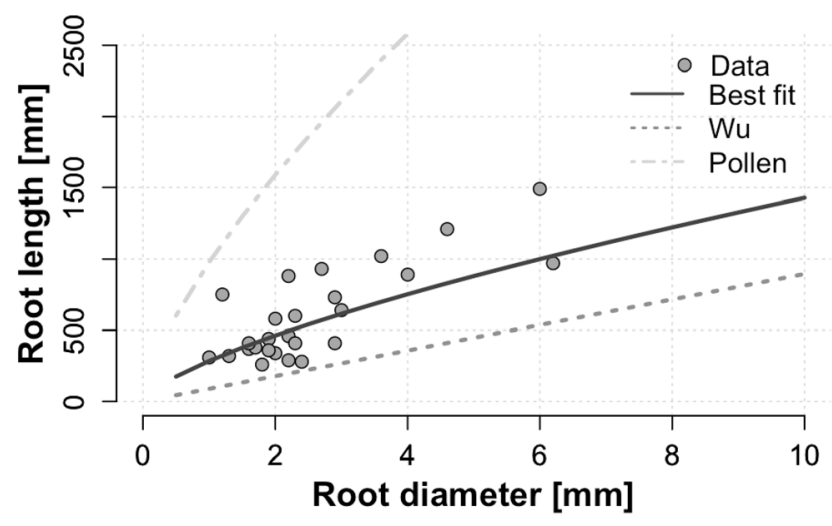

Figure 3. Measured data of 27 secondary lateral roots of spruce (Picea abies L.) trees (circles) and fitted empirical equation (equation (1), solid black line). Dashed and dashdotted gray lines show empirical models used by $W u$ et al. [1988] for various tree species and by Pollen [2008] for herbaceous species, respectively. The fitting of equation (1) has a residual standard error of 217 on 25 degrees of freedom, a sum of squared (SSE) errors of 216 , and a $R^{2}$ value of 0.63 . 


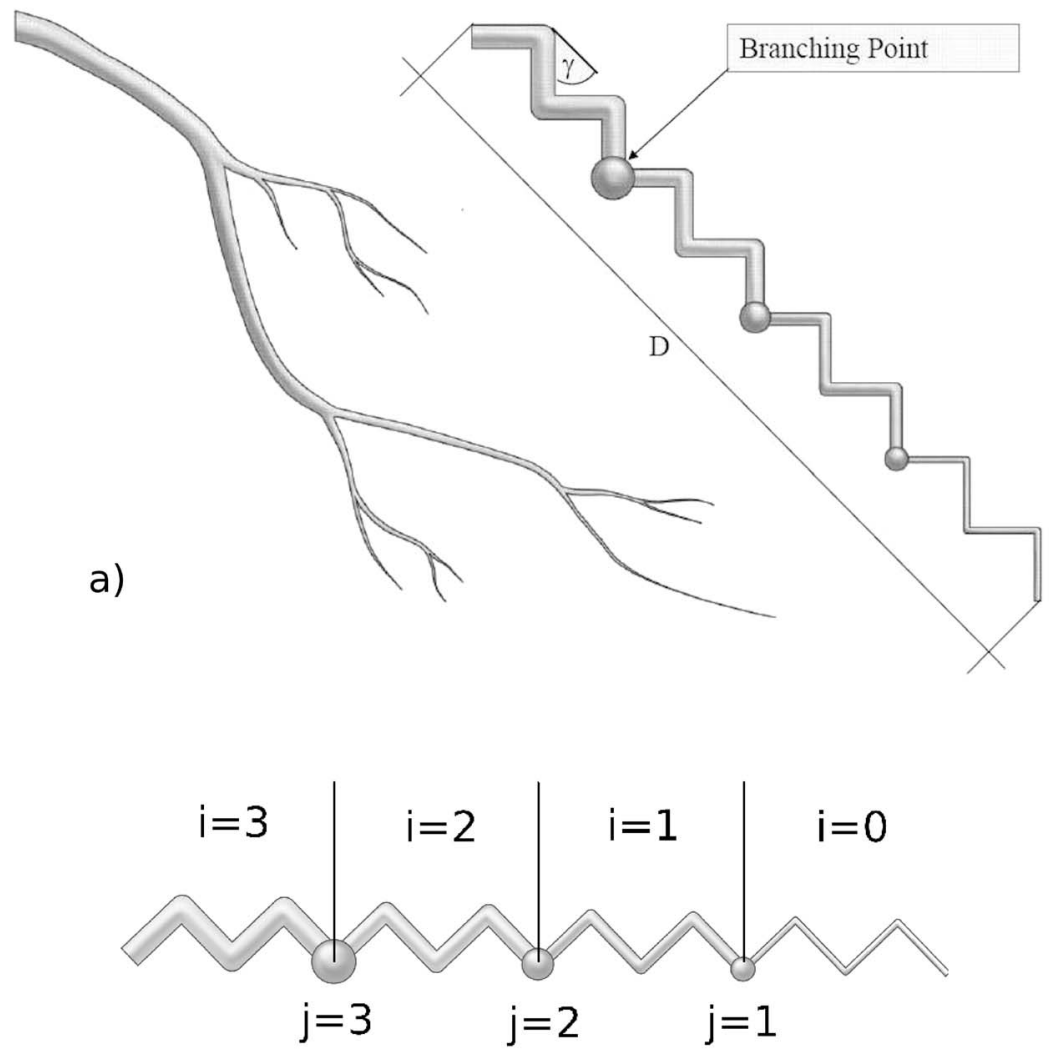

b)

Figure 4. (a) Root geometry and root analogue. The branching points are represented as spheres with a dimension proportional to the root segment diameter. (b) Notation for a four-segment root $(n=3)$.

[13] A root has $n$ branching points and $n+1$ root segments (Figure 4). The mean branching distance or mean segment length is

$$
b=L /(n+1) .
$$

Each root segment is assumed to have a constant diameter. In this study we consider the branching distance to be constant. The root diameter is assumed to increase from a minimum of $1 \mathrm{~mm}$ at the root tip $\left(d_{0}\right)$ to a maximum value of $d_{n}$ at the other end.

[14] The root cross-sectional area along the root length is calculated as

$$
A_{i}=s(i+1) A_{0}, \quad 1 \leq i \leq n,
$$

where $A_{i}$ is the cross-section area of root segment $i, A_{0}$ is the cross-sectional area of root segment 0 (equal to $\pi / 4 \mathrm{~mm}$ since $d_{0}=1 \mathrm{~mm}$ ), and $s$ is a scaling factor. Since the scaling factor (or so-called root diameter proportionality factor) [Van Noordwijk et al., 1994; Ozier-Lafontaine et al., 1999; Vercambre et al., 2003; Collet et al., 2006] is defined as

$$
s=\frac{b}{L} \frac{A_{n}}{A_{0}},
$$

the root diameter of segment $i$ is given by [Schwarz et al., 2009]

$$
d_{i}=d_{0} \sqrt{s(i+1)}, \quad 1 \leq i \leq n .
$$

[15] Root tortuosity is represented by dividing a root segment into connected subsegments that meet at an angle $\gamma$ (Figure 4) given by

$$
\gamma=\cos ^{-1}\left(\frac{1}{z}\right)
$$

where $z$ is a tortuosity factor defined as

$$
z=\frac{L}{D},
$$

and $D$ is the straight distance between the root tip and the pull location (Figure 4). For simplicity we assume that tortuosity is identical for all segments.

\subsection{Individual Root Mechanics}

[16] Mechanically, each root is characterized by a maximum tensile strength, $T^{\max }$, and intrinsic Young's modulus, $E_{f}$, that depend on root diameter. Numerous data indicate that $T^{\max }$ is proportional to the root diameter to some power, namely,

$$
T^{\max }=\alpha d^{\beta},
$$

where $\alpha$ and $\beta$ are fitted coefficients. This equation is also valid for individual root segments of diameter $d_{i}$. Table 1 shows values of these coefficients for spruce species (Picea 
Table 1. Published Values of Coefficients $\alpha$ and $\beta$ in Equation (8) for $T^{\max }$ in Megapascals and $d$ in Millimeters

\begin{tabular}{lcc}
\hline \multicolumn{1}{c}{ Reference } & $\alpha$ & $\beta$ \\
\hline Abernethy and Rutherfurd [2001] & 49.4 & -0.8 \\
Bischetti et al. [2005] & 28.1 & -0.7 \\
Genet et al. [2008] & 37.9 & -0.5 \\
\hline
\end{tabular}

sp.) reported by several authors [Abernethy and Rutherfurd, 2001; Bischetti et al., 2005; Genet et al., 2008].

[17] To estimate Young's modulus, we use the formula of Schwarz et al. [2010] that best fits data found in the literature

$$
E_{f}=696 d^{-1},
$$

where $E_{f}$ is Young's modulus in MPa and $d$ is in millimeters. This equation also applies to individual root segments of diameter $d_{i}$. The apparent elasticity of a root results from the combined effects of elasticity of the root itself $\left(E_{f}\right)$, and the root tortuosity $\left(E_{t}\right)$. While the extension due to the root itself is limited by the maximum tensile strain at strength threshold $T^{\text {max }}$, the extension due to tortuosity may not exceed a strain of $z-1$, typically around $10-20 \%$ [Commandeur and Pyles, 1991]. Considering the common elasticity formulation, we thus define an apparent Young's modulus $\left(E_{\text {app }}\right)$ as

$$
E_{\text {app }}=E_{f}+E_{t} .
$$

Assuming that $E_{\mathrm{t}}$ is linearly proportional to $E_{\mathrm{f}}$ (where the ratio $\lambda=E_{\mathrm{t}} / E_{\mathrm{f}}$ depends on tortuosity and soil compressibility, the so-called compression index) [Commandeur and Pyles, 1991], equation (10) reduces to

$$
E_{\text {app }}=E_{f}(1+\lambda) .
$$

We assume that, in each root segment $i$, the resulting strain $\varepsilon_{i}$ is the sum of the two strain components due to root stretching and tortuosity. Using equation (11)

$$
\varepsilon_{i}=\frac{\lambda+1}{\lambda} \frac{f_{i}^{\mathrm{tot}}}{A_{i} E_{\mathrm{f}, \mathrm{i}}},
$$

where $f_{i}^{\text {tot }}$ is the total tensile force transmitted by the root segment $i$ and calculated iteratively in the algorithm (see Appendix A), $A_{i}$ is the cross-section area of the segment, and $E_{\mathrm{f}, \mathrm{i}}$ is the Young's modulus of the root material.

\subsection{Root-Soil Interfacial Friction}

[18] Friction at the root-soil interface depends on soil type, soil moisture and confining pressure. We distinguish two major sources of friction: friction at the root-soil interface and friction at branching points. Interfacial friction changes from static friction during the stretching phase of a pullout test, to dynamic friction during the slip out phase. Furthermore, based on studies of fiber-reinforced concrete [e.g., Naaman et al., 1991] static friction may be separated into bonded and debonded friction.

\subsubsection{Bonded Friction}

[19] In this section we show why bonded friction can be neglected following the approach of Naaman et al. [1991].
Bonded friction is considered a perfectly elastic response to local slip between the fiber and the matrix resulting in a frictional resistance at the fiber-matrix interface of the form

$$
\tau_{b}=k S,
$$

where $\tau_{b}$ is bonded friction, $k$ is the bond modulus, and $S$ is the local slip which depends on the difference between fiber and matrix Young's moduli, $E_{f}-E_{m}$ (details of this formulation can be found in the work by Naman et al. [1991]). When $\tau_{b}$ reaches the critical value of $\tau_{b}^{\max }$, a debonding crack grows along the fiber-matrix interface (Figure 5).

[20] An illustration of how bonded friction varies along a constant diameter root after a debonding crack has begun to grow is shown in Figure 6. Integration of friction yields the total frictional force on a root. Even for parameters values that maximize the effect of bonded friction $\left(k=10^{9} \mathrm{~Pa} \mathrm{~m}^{-1}\right.$, $\tau_{b} \max =50 \mathrm{kPa}, E_{f} / E_{m}=10^{-3}$ ) the component of bonded friction to the total frictional force is relatively small (Figure 6).

a.

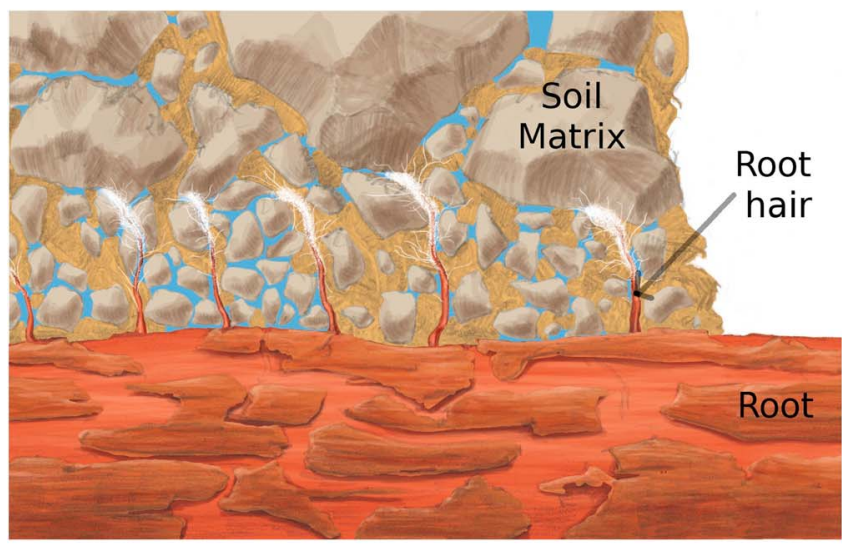

b.

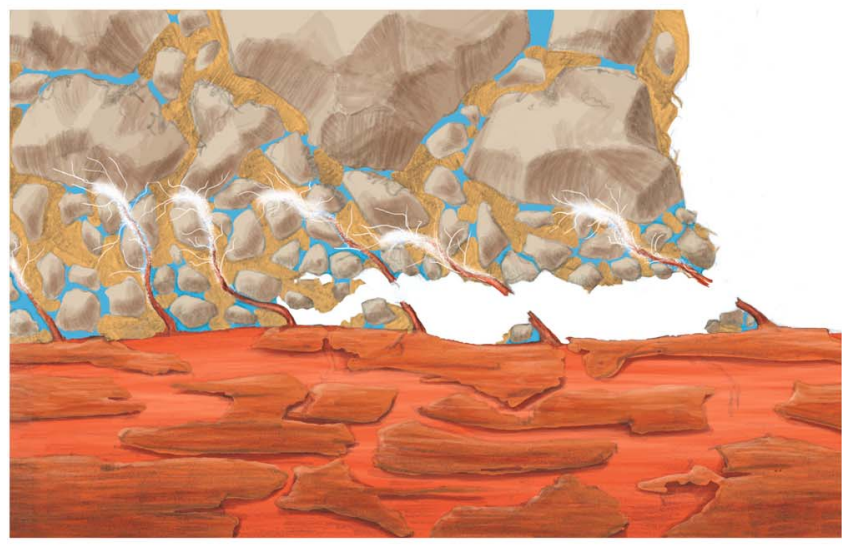

Figure 5. ( $a$ and $b$ ) Hypothetical illustration of the propagation of a debonding crack at the instance when bonds between the fiber and the surrounding matrix reach a critical shear displacement. 


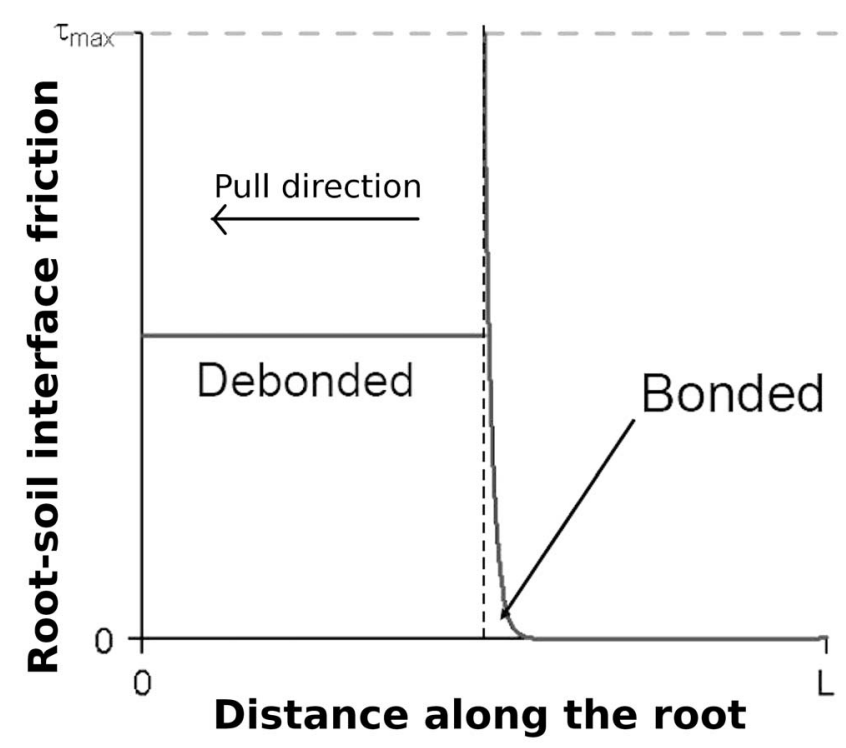

Figure 6. Distribution of friction along a root when the debonded crack extends to half the root length. Calculations were made with $k=10^{9} \mathrm{~Pa} \mathrm{~m}^{-1}, \tau_{\max }=50 \mathrm{kPa}$, and $E_{f} / E_{m}=10^{-3}$.

[21] When a root is stretched, its radius is reduced due to radial contraction given by

$$
\Delta d=\varepsilon_{f} \nu_{f} d,
$$

where $\Delta d$ is radial contraction, $\varepsilon_{f}$ is the fiber local strain, and $\nu_{f}$ is Poisson's ratio. Since

$$
\varepsilon_{f}=\frac{F}{\pi(d / 2)^{2} E_{f}},
$$

where $F$ is the pull out force applied to the root in [N], we can calculate the value of $\Delta d$ along the root. With $d=2 \mathrm{~mm}$, $E_{f}=10^{6} \mathrm{~Pa}$ [Schwarz et al., 2010], $\nu_{f}=0.3$ [Dupuy et al., 2005; Hamza et al., 2007], and $F=10 \mathrm{kN}$ (maximum value of pullout force based on our analysis), the Poisson effect is at most $10 \%$ of the root diameter. The decrease in diameter promotes debonding thereby further reducing the bonded zone between the fiber and the matrix. Thus, we can safely neglect bonded friction in our calculations as suggested earlier by Ennos [1990] and $L i$ [1994].

\subsubsection{Debonded Friction}

[22] Some authors have used a constant value for the rootsoil friction (what we call here debonded friction) in the range of 1 to $10 \mathrm{MPa}$ [e.g., Waldron and Dakessian, 1981; Abe and Ziemer, 1991]. In the RBM, the debonded friction is calculated assuming that failure occurs when the Coulomb failure criterion is reached, i.e.,

$$
\tau_{d}=c^{\prime}+\sigma^{\prime} \tan \phi
$$

where $\tau_{d}$ is debonded friction, $c^{\prime}$ is the apparent cohesion, $\sigma^{\prime}$ is the effective normal stress, and $\phi$ is the residual root-soil friction angle. The effective normal stress on a root segment depends on tortuosity because the pullout force transferred to a tortuous root has a component which is always per- pendicular to the root segment, leading to an asymmetrical local increase of the normal stress. To include this effect, for each segment, we replace $\sigma^{\prime}$ by $\sigma_{\text {tort,i, }}^{\prime}$, defined as

$$
\sigma_{\mathrm{tort}, \mathrm{i}}^{\prime}=\sigma^{\prime}+\left(\frac{f_{i-1}^{\mathrm{tot}} \sin \gamma}{\pi d_{i} b}\right)
$$

where $f_{i-1}^{\text {tot }}$ is the pullout force acting on all activated root segments with index less than $i$. This quantity is known when computing $\sigma_{\text {tort }}^{\prime}$ for segment $i$.

[23] When only the first root segment is activated, then the effect of tortuosity is neglected. For vertical pullout tests, the confining pressure around a root segment also varies as a function of soil depth.

[24] Considering a single root segment $i$, the component of pullout force due to root-soil interfacial friction $\left(f_{i}^{\text {if }}\right)$ is

$$
f_{i}^{\mathrm{if}}=\pi b \tau_{d} d_{i}
$$

If instead of root segments of different diameters as assumed in the RBM, the root diameter is a continuous function of distance along the root $(d=d(x))$, then the cumulative rootsoil interfacial friction $\left(F^{\mathrm{if}}\right)$ along the root can be calculated as

$$
F^{\mathrm{if}}=\pi b \tau_{d} \int_{0}^{l} d(x) d x
$$

where $l$ is distance along the root, and

$$
d(x)=d_{0} \sqrt{\frac{s}{b} x} .
$$

Substituting equations (20) into (19) yields

$$
F^{\mathrm{if}}(l)=\frac{2}{3} b \tau_{d} d_{0} \sqrt{\frac{s}{b}} l^{3 / 2} .
$$

\subsubsection{Effect of Soil Saturation}

[25] The effect of unsaturated soil conditions is implemented using Bishop's effective stress approach $[L u$ and Likos, 2006]:

$$
\sigma^{\prime}=\sigma-u_{a}+\chi\left(u_{a}-u_{w}\right),
$$

where $\sigma^{\prime}$ is the effective normal stress, $\sigma$ is the total normal stress, $u_{a}$ is the air pressure (assumed equal to 0 in our calculations), $u_{w}$ is the pore water pressure, and $\chi$ is the effective stress parameter assumed to be a function of the degree of saturation [Lu and Likos, 2006] with values ranging between 0 (dry) and 1 (fully saturated). Here we assume a linear relation between matric suction $\left(u_{a}-u_{w}\right)$ and the suction stress $\chi\left(u_{a}-u_{w}\right)$ as shown by Lu and Likos [2006]. We also assume that once the water content reaches a minimal threshold value (dry condition), suction stress drops to 0 for sandy soil or remains constant for clay and loamy soil at a value corresponding to the effects of cementation. We recognize that the effects of soil saturation are more complex, especially for fine-textured soils. Changes in saturation in fine-textured soils modify strength properties as well as deformation characteristics, leading to onset of plasticity as summarized in a recent study by Nuth and 
Laloui [2008]. Moreover, it may also introduce time and pullout rate dependency as described in the rheological framework of Ghezzehei and Or [2000]. For simplicity we defer such constitutive relationships to future studies and focus on standard applications as described next. We use the following equations to calculate the effect of suction on apparent cohesion as a function of water content

$$
\begin{gathered}
c^{\prime}=c_{\max }^{\prime}\left(\frac{\theta_{\text {sat }}-\theta}{\theta_{\text {sat }}-\theta_{\min }}\right), \quad \theta \geq \theta_{\min }, \\
c^{\prime}=c_{\text {res }}^{\prime}, \quad \theta<\theta_{\min },
\end{gathered}
$$

where $c^{\prime}$ is the apparent cohesion due to suction and cementation effects, $c_{\text {res }}^{\prime}$ is the residual cohesion in dry conditions and $c_{\text {max }}^{\prime}$ is the maximum value of apparent cohesion that a soil type may reach in optimal water content conditions. For sand $c_{\text {max }}^{\prime}$ ranges between 1 and $5 \mathrm{kPa}$ [Goulding, 2006] while for clay $c^{\prime}$ max may have a wide range of values which range in the order of tenths of $\mathrm{kPa}$.

\subsubsection{Dynamic Friction}

[26] If during pullout, the maximum tensile strength of a root is not exceeded, the root slips out and frictional forces are initially reduced due to system dynamics. This decrease is due primarily to breakage and deformation of small lateral root hairs, rearrangement of soil particles, and changes in the value of the confining pressure, but also to the reduction of the length of the root embedded in the soil. To take these latter effects into account, we introduce a frictional decay function which depends on embedded root length, as proposed by Naaman et al. [1991] and Cuhna et al. [2008]. The dynamic component of the root-soil interfacial friction is then

$$
\tau_{\mathrm{dyn}}=c \tau_{d}\left(\frac{D\left(1+\varepsilon^{\max }\right)-\Delta x}{L}\right)^{\zeta}+(1-c) \tau_{d},
$$

where $\tau_{\text {dyn }}$ is dynamic friction, $\varepsilon^{\max }$ is the maximum strain a root can sustain, and $c$ and $\zeta$ are empirical coefficients. Using literature data of pullout tests of willow's roots in sand [Mickovski et al., 2007], the best fit to equation (25) results in values of $c$ in the range of 0 to 1 (with the range depending on soil type and conditions). The exponent $\zeta$ takes on values between 1 and 10 . These two coefficients determine the decay of dynamic friction during slip out. For $c=0$ there is no change between the static and the dynamic root-soil interfacial friction. For large $\zeta$, root-soil interfacial friction decays exponentially.

\subsection{Branching Point Friction}

[27] Root branching points are represented as spherical elements that increase root-soil interfacial friction. The estimation of this component of friction is based on the following empirical observations and assumptions: (1) the angle between main and side roots at branching point has no influence [Dupuy et al., 2005], (2) the mean diameter of the branching point is larger than any connected root segments and is a function of the largest root segment diameter, and (3) the elasticity of lateral roots is neglected and their activated pullout force is considered constant. Based on infor- mation found in the literature [e.g., Stokes et al., 1996; Dupuy et al., 2005], we calculate the additional frictional force due to branching point $i$ on segment $i$ as

$$
f_{i}^{b p}=Y d_{i}
$$

where $Y$ is an empirical branching coefficient. Combining interfacial and branching point friction, the contribution of a root segment to the maximal pullout force is

$$
f_{i}=\pi d_{i} b \tau_{d}+Y d_{i}
$$

The total pullout force transmitted to the root segment $i$ is

$$
f_{i}^{\mathrm{tot}}=\sum_{j=1}^{i} f_{j}
$$

Again assuming a straight root and activation of all root segments, the maximum pullout force is

$$
F_{\max }^{\mathrm{tot}}=\pi d_{o} b \tau_{d}+\sum_{i=1}^{n} f_{i}
$$

or, substituting equation (27),

$$
F_{\max }^{\mathrm{tot}}=\pi d_{o} b \tau_{d}+\left(\pi b \tau_{d}+Y\right) \sum_{i=1}^{n} d_{i}
$$

\section{Pullout Model for Individual Roots}

[28] The complete pullout force as a function of pullout displacement is obtained by simulating a quasi-static pullout experiment where the pullout force is computed during stepwise strain increments. A strain loading approach is necessary to calculate the pullout forces in both the stretching and slip out phases. Stress loading provokes the complete failure of the bundle at the maximum pullout force and hence cannot model the slip out phase. Moreover, displacement can be calculated only for a special case where all the root diameter classes have the same apparent elasticity.

[29] Here we describe in details the algorithm to compute the pullout force for an individual root as a function of incremental displacement. This algorithm is characterized by two main loops: (1) a stretching and breaking phase loop and (2) a slipping out phase loop (Figure 7). Initially a root supports no load. During the initial stretching of a root, the pullout force required for matching root strain at a given strain step is calculated through an iterative process that considers progressive increments of activated root lengths. The algorithm used during the stretching phase (see Appendix A) is as follows:

[30] 1. Initialization

[31] (i) Given a root of diameter $d$ compute its length ( $L$, equation (1)) and its cross-sectional area $\left(A_{n}\right)$.

[32] (ii) Given the number of segments $(n+1)$, compute the mean branching distance ( $b$, equation (2)).

[33] (iii) Compute the scaling factor ( $s$, equation (4)).

[34] (iv) For each segments, compute segment diameter $\left(d_{i}\right.$, equation (5)) and maximum tensile strength $\left(T_{\max }\right.$, equation (8)). 


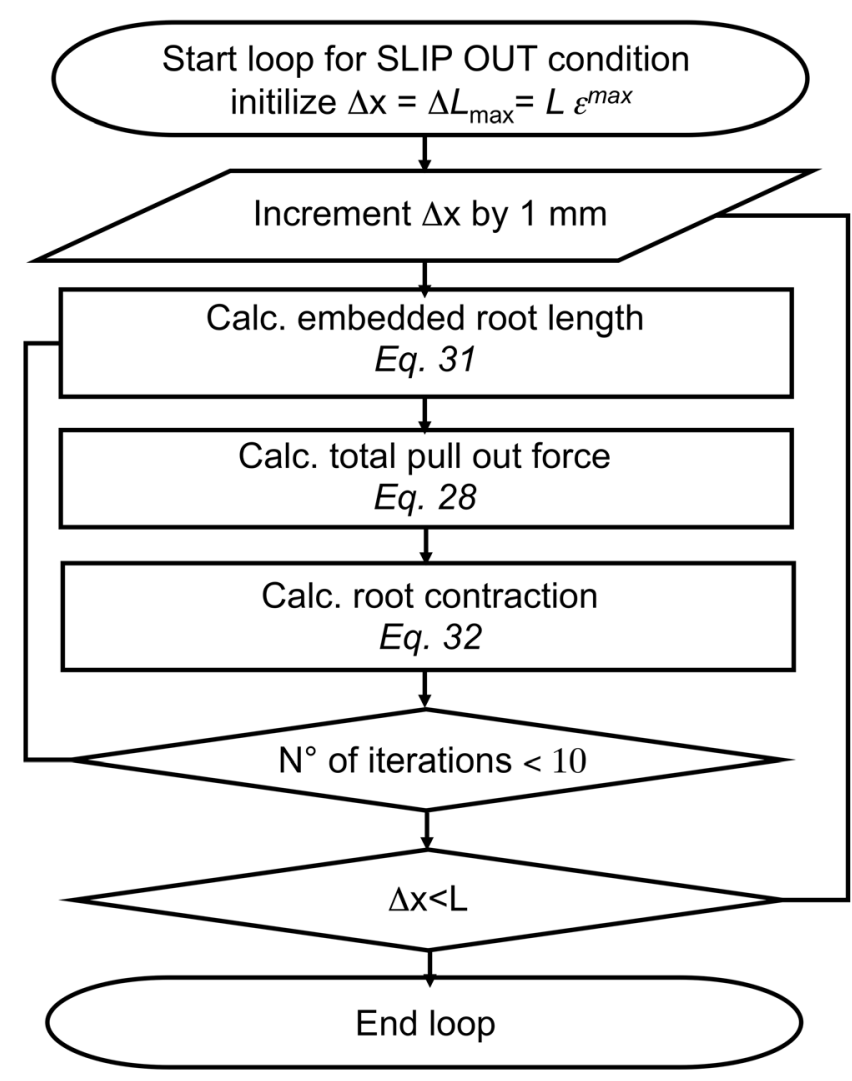

Figure 7. Flowchart of the module of the model used to calculate the pullout force in the slip out phase of the force-displacement behavior of an individual root.

[35] 2. Displacement loop with increment $\Delta x$. Loop over activated segments (starting from segment $n$ ). Start the loop which defines the condition for the activation of the rootsoil interfacial friction. Starting from the root segment $n$, verify if the actual value of root elongation is lower than the imposed displacement. If yes, then consider one more root segment and recalculate the root elongation (next item) until the slip out condition (all segments are activated and you move to a new loop for the calculations of the slipping phase) or the breakage conditions (total pullout forces bigger than the maximal tensile force of the root, calculated with $\left.T_{\max }\right)$, otherwise print out the calculated/initialized values and go back to the beginning of the beginning of the loop for the next strain step.

[36] 3. Start the loop for the calculation of root elongation. The loop cumulate the frictional forces and the root segment elongation calculated from the smallest activated root segment (defined in point $\mathrm{f}$ ) to the bigger root segment $(n)$. Within this loop (1) root segment diameter $\left(d_{i}\right)$ is calculated with equation (5); (2) root segment interfacial friction is calculated with equation (18), where the debonded friction $\left(\tau_{d}\right)$ is calculated with equations (16), (17), (22)), (23) and (24)); (3) root segment branching friction $\left(f_{i}^{b p}\right)$ is calculated with equation (26); (4) the apparent Young's modulus of the root segment is calculated with equation (10), in function of the root segment diameter $\left(d_{i}\right)$; and (5) the root elongation is calculated with equation (12) using the cumulative force $f_{i}^{\text {tot }}$ calculated considering all the frictional forces and branching point forces.
[37] The algorithm is repeated until either the root fails or slips. If cumulative friction exceeds the maximal tensile force of a root segment (estimated using equation (8)), the root breaks. If all root segments have been activated and the maximal tensile strength is not reached, then the root starts to slip out and the algorithm in Figure 7 is used. This algorithm calculates the pullout force of the root in the slipping phase considering the progressive reduction of root length embedded in the soil and the axial contraction of the root due to the decreased tensile stress transmitted through the root segments.

[38] The reduction of embedded root length is calculated as

$$
\Delta L_{\mathrm{em}}=D\left(1+\varepsilon^{\max }\right)-\Delta x,
$$

where $\Delta L_{\mathrm{em}}$ is the change of the embedded root length at the displacement $\Delta x$, and $\varepsilon^{\max }$ is the maximal strain reached by a root at the instance where slip begins. We assume that prior to root slippage, embedded root length is equal to $L$ (in reality, part of the root is already out of the soil because of tortuosity). Root contraction is calculated using the difference between the strains reached at maximal and minimal pullout force according to

$$
\Delta L_{\text {con }}=L\left(\varepsilon^{\max }-\varepsilon^{\text {slip }}\right),
$$

where $\varepsilon_{f}^{\text {slip }}$ is calculated iteratively using equations (12) and (28), considering an initial number of embedded root segments equal to $L_{\text {slip }} / b$, where at the beginning $L_{\text {slip }}=L-$ $\Delta L_{e m}$. The resulting root length along which frictional forces remain active during slippage $\left(L_{\text {slip }}\right)$ is calculated for a prescribed number of iterations (usually 10 ), according to

$$
L_{\text {slip }}=L-\Delta L_{\mathrm{em}}-\Delta L_{\mathrm{con}} .
$$

[39] With the new embedded root length $\left(L_{\text {slip }}\right)$, we recalculate friction and total pull out force (equation (29)) over $n$ activated root segments where $n=L_{\text {slip }} / b$. As the total pull out force acting on a root decreases (smaller embedded root length), the root contracts, further decreasing the length of embedded root and thus total friction. The macroscopic consequence of this iterative force balance is also known as stick-slip effect.

\section{Pullout Model for Root Bundles}

\subsection{Root Distribution Model}

[40] The global mechanical behavior of a root bundle is strongly influenced by the distribution and size of roots. Data on distribution of roots of different diameter classes are scarce [e.g., Moroni et al., 2003; Wu et al., 1988; Zhou et al., 1998]. Thus, we parametrize root distribution using the noncumulative Weibull probability function

$$
p(d ; m, k)=\frac{m}{k^{m}} d^{m-1} \exp \left[-\left(\frac{d}{k}\right)^{m}\right]
$$

with $p(d)$ is the probability that a mapped root in a profile belongs to the root diameter class $d$, and $m$ and $k$ are the shape and scale parameters of the Weibull probability density function, respectively. We chose the Weibull probabil- 

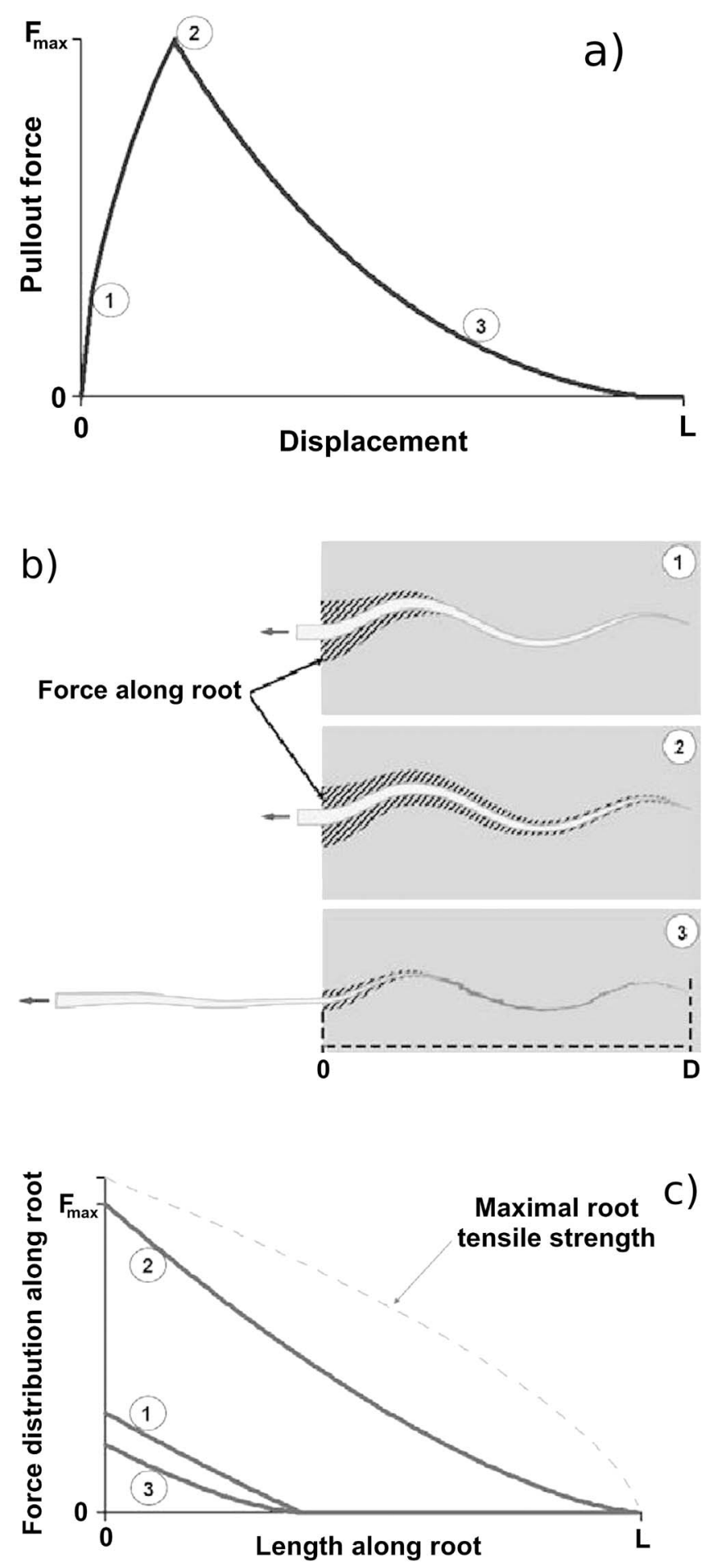

Figure 8. (a) Force-displacement behavior of a $2 \mathrm{~mm}$ diameter root calculated using the RBM. The three numbered points indicate the positions which correspond to (b) the three illustrations of the slipping root and (c) the three curves showing the cumulative force distribution along the root length.

ity function due to its well-established analytical formulation which may be adapted to various shapes of experimental distributions (in this case better than the lognormal distribution), and because it tends to fit better the distribu- tion of big root diameter classes that are more important for mechanical considerations.

[41] This application of the Weibull probability function for the parametrization of the root distribution assume that the shape of the probability function remains identical for roots at different radial distances from the tree stem; the only parameter that changes with distance from the tree stem is the total number of roots found at each distance.

\subsection{Root Bundle Model}

[42] Recent studies [Pollen and Simon, 2005] show the potential utility of the Fiber Bundle Model (FBM) as a realistic framework for estimation of root reinforcement in river banks. The classical approach of the FBM consists of simulation of a stress loading step of a bundle of fibers, where each fiber has different maximal tensile strength. In the simplest application, the fibers are considered to have identical length, which makes it possible via a global load sharing rule (uniform transfer of loads of broken fibers to all other fibers in the bundle) to compute analytically the entire stress-strain behavior. However, differences in geometries and in mechanical properties of individual roots may be important and complicate global pullout mechanical behavior of real root bundles. For these reasons, the assumptions of constant Young's modulus and constant root length are unrealistic and may distort the mechanical response of root systems and their failure dynamics as related to triggering a landslide. By calculating mean values of pullout forcedisplacement behavior of different root diameter classes, we may relax some of the assumptions and consider roots of variable lengths and mechanical properties. The resulting total pullout force of a bundle of roots as a function of displacement can be expressed as a sum of pullout forces of individual roots,

$$
F_{\text {bundle }}(\Delta x)=\sum_{j=1}^{N} F_{j}(\Delta x) n_{j},
$$

where $F_{j}(\Delta x)$ is the pull out force of a root belonging to diameter class $j$, and $n_{j}$ is the number of roots present in the bundle of diameter class $j . N$ is the number of diameter classes. $F_{j}(\Delta x)$ is calculated for each root diameter class using the individual root pullout module. This formulation of the Root Bundle Model (RBM) may be defined as a strain step loading model. In effect, we assume that roots bridging a crack are loaded under tension with no interaction between neighboring roots. We also assume that the orientation of roots has no effect on pullout forces.

\section{Results}

\subsection{Individual Root Behavior}

\subsubsection{Pullout Phases}

[43] Figure 8 shows the different pullout phases calculated for a root without branching points during slip out. In the first part of the force displacement curve the stretching phase is nonlinear due to the progressive increase of activated root length. This nonlinear elastic behavior has also been observed in field and laboratory experiments [e.g., Ennos, 1990; Hamza et al., 2007]. The point labeled 1 in Figure 8 indicates a point when only part of the root-soil 


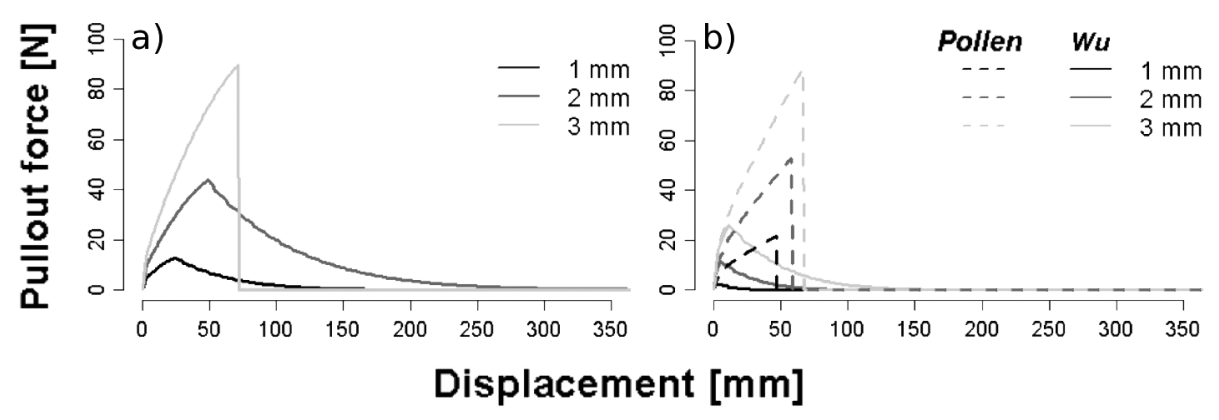

Figure 9. Pullout forces versus displacement of representative individual roots with diameters of 1, 2, and $3 \mathrm{~mm}$, used for the calculation of root bundle behaviors. (a) Results with $2 \mathrm{kPa}$ of confining pressure, $25^{\circ}$ of root-soil interfacial friction angle, saturation of 0.9 , tortuosity of 1.1, and branching coefficient of 0.4 (also used as standard values in the sensitivity analysis). (b) A comparison of pullout behavior of individual roots using two different equations to estimate root length (Wu et al.'s [1988] and Pollen's [2008] models). The diameters of the individual roots are listed in the legend.

interface friction has been activated. At the point labeled 2, all the root is activated and the maximum pullout force is reached. The dotted gray line in Figure $8 \mathrm{c}$ shows that the maximal tensile strength along the root is never reached, thus the root slips out rather then breaks. Had the black continuous line associated with the point labeled 2 crossed above the gray dotted line, the root would have been broken (this could have happened had the root been longer, rootsoil interfacial friction been higher, or root strength been weaker). The force distribution at point labeled 2 shows that root failure is most likely where the root is pulled. Under natural conditions this may not always be true due to heterogeneity of root material, root geometry, and root-soil interactions. Finally, the point labeled 3 indicates the moment where the embedded root length during the slip out phase is equal to the activated root length at the point labeled 1. Figure $8 \mathrm{c}$ shows that the total pullout force at these two instances is different. This is because during the stretching phase the diameters of the activated root segments are larger than those activated during the slip out phase; with more root-soil interfacial area, the total friction is larger. The reduction of root diameter along the root partly explains the exponential decay of the pullout force during the slip out phase.

\subsubsection{Sensitivity Analyses of Pullout Mechanical Behavior}

[44] Theoretical calculations of pullout behaviors of three roots of three different diameter classes $(1,2$, and $3 \mathrm{~mm})$ are shown in Figure 9. In Figure 9a the force-displacement curves show that small roots tend to slip out while larger roots tend to break. This result, however, depends on the nature of the relations used for estimating root length from root diameter. Figure 9b shows force-displacement curves obtained with two different root-length models found in the literature. In the case of $W u$ et al.'s [1988] model (see Figure 3), root-length estimates are small and roots do not break. In contrast, Pollen's [2008] model (Figure 3) for herbaceous plants yields relatively long roots that tend to break. Figure 9 also shows that the maximal pullout force and the displacement at maximal pullout force vary nonlinearly with root diameters, thus showing that the apparent Young's modulus change as a function of the root diameter.

[45] Figure 10 shows the influence of root diameter along its length on the pullout behavior of individual roots. Roots with constant diameters have higher total friction due to their larger surface areas than roots whose diameters decrease toward their tips. This difference in the total rootsoil interfacial friction influences both the threshold of the

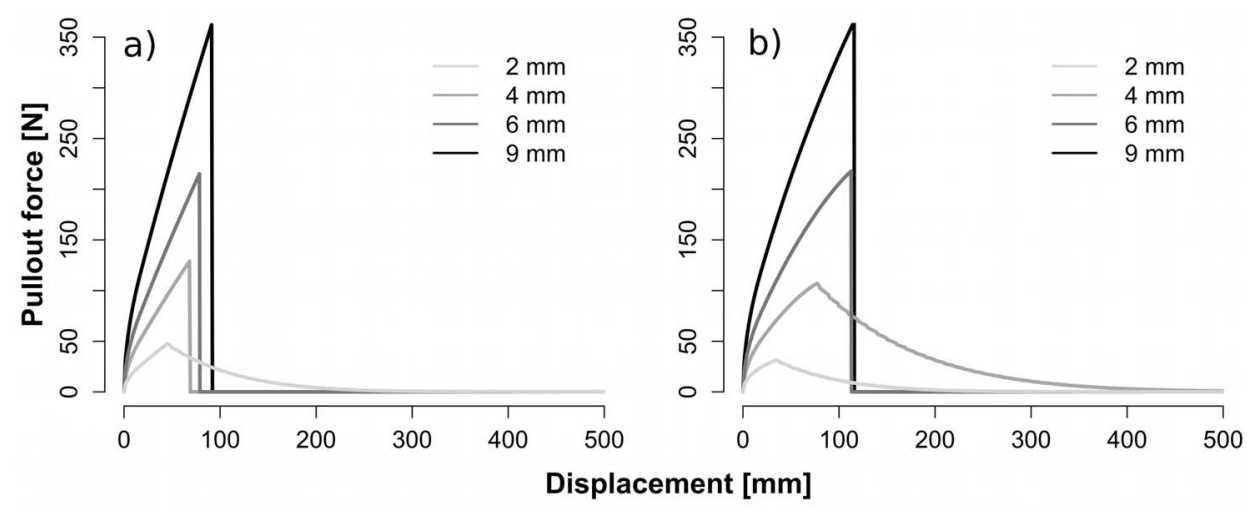

Figure 10. Comparison between numerical simulation considering (a) constant or (b) variable root diameter along the root axes. Calculations were done for $2 \mathrm{kPa}$ confining pressure, soil saturation degree of 0.9 , root-soil friction angle of $25^{\circ}$, and a factor of tortuosity of 1.1 . 


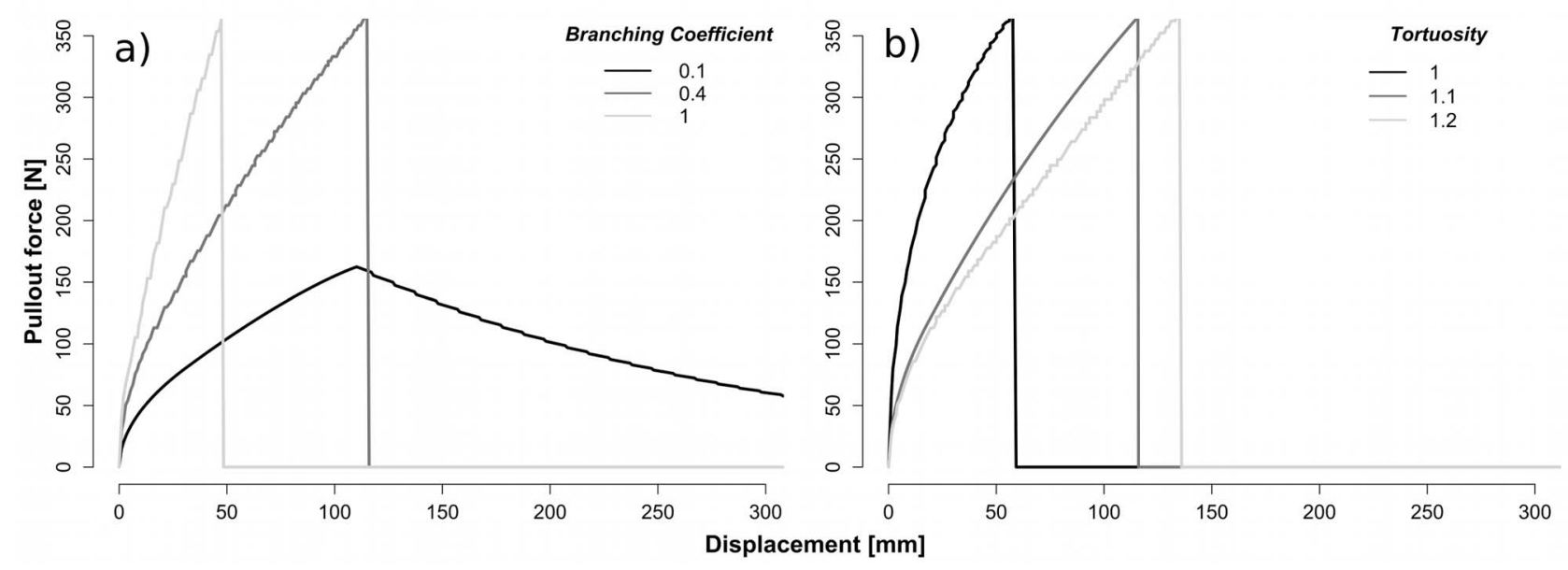

Figure 11. Influence of two parameters on pullout behaviors of an individual root (with $9 \mathrm{~mm}$ diameter): (a) branching point coefficient and (b) tortuosity. Low values of branching coefficient indicate low friction due to branching points, whereas increasing values of tortuosity indicate increased tortuosity of the root.

slipping out root diameter class (see the $4 \mathrm{~mm}$ diameter root in Figure 10), and the apparent cohesion of the breaking root classes.

[46] To complete the picture of individual root mechanical behavior, we performed sensitivity analyses of some key mechanical and geometrical parameters to identify the most sensitive ones. Parameters such as confining pressure and root-soil interfacial friction angle had low influence on the global pullout behavior of individual roots. The maximal pullout force changed by less than $10 \%$ when considering extreme range of values for these two parameters $\left(15-45^{\circ}\right.$ for the root-soil interfacial friction angle, and $0-10 \mathrm{kPa}$ for the confining pressure). Results in Figure 11 show strong influences of two other parameters: root branching coefficient $(Y)$ and root tortuosity $(z)$. As base values for the calculations we have used $2 \mathrm{kPa}$ for soil confining pressure (equivalent to $10-20 \mathrm{~cm}$ soil depth), tortuosity value of 1.1 , friction angle of $25^{\circ}$, branching point coefficient $(Y)$ of 0.4 (calibrated with field pullout tests of roots with diameters ranging from 1 to $3 \mathrm{~mm}$ in diameter), and degree of saturation value of $90 \%$ (close to saturation). In Figure $11 \mathrm{a}$, we observe that an increase in the value of the branching coefficient leads to an increase of the total friction of the roots. Consequently, the activated root length decreases and so does the apparent elasticity. A strong variation of the global friction influences the type of pullout out behavior, as illustrated in Figure 11a: for a branching coefficient greater than 0.4 roots tend to break while for a branching coefficient of 0.1 roots tend to slip out.

[47] Commandeur and Pyles [1991] illustrated the importance of tortuosity on the material (Young's) moduli. Figure $11 \mathrm{~b}$ shows the influence of this parameter on the pullout behavior of individual roots when root-soil interfacial friction is also considered. An increase in tortuosity leads to an increase from 5 to $14 \mathrm{~cm}$ of displacement at failure while the maximal pullout force remains constant at $350 \mathrm{~N}$.

[48] The influence of soil moisture depends on soil type. For loamy soils the maximal soil cohesion is about $10 \mathrm{kPa}$ at $10 \%$ saturation, and residual cohesion is $5 \mathrm{kPa}$ for dry conditions (less than 10\% saturation) [Schwarz et al., 2010]. In this case, the variation of maximal pullout force is about $10 \%$, while the variation of displacement at maximal pullout force is about $20 \%$.

\subsection{Root Bundle Mechanical Response}

\subsubsection{Comparison Between Single and Root Bundle}

[49] Erosion mitigation and slope stabilization studies often consider small roots as more effective than larger roots in slope stability [e.g., Reubens et al., 2007]. Results in Figure 12 provide new insights into this question and show that to obtain mechanical reinforcement equivalent to one $20 \mathrm{~mm}$ diameter root, 23 roots with diameters of $2 \mathrm{~mm}$ are needed. Other differences between the behaviors of the two types of root reinforcement are (1) the displacement at the maximal pullout force differs by about $50 \mathrm{~mm}$ and (2) because a $20 \mathrm{~mm}$ diameter root is considerably longer than a $2 \mathrm{~mm}$ diameter root ( $2.5 \mathrm{~m}$ against $0.46 \mathrm{~m}$, using our

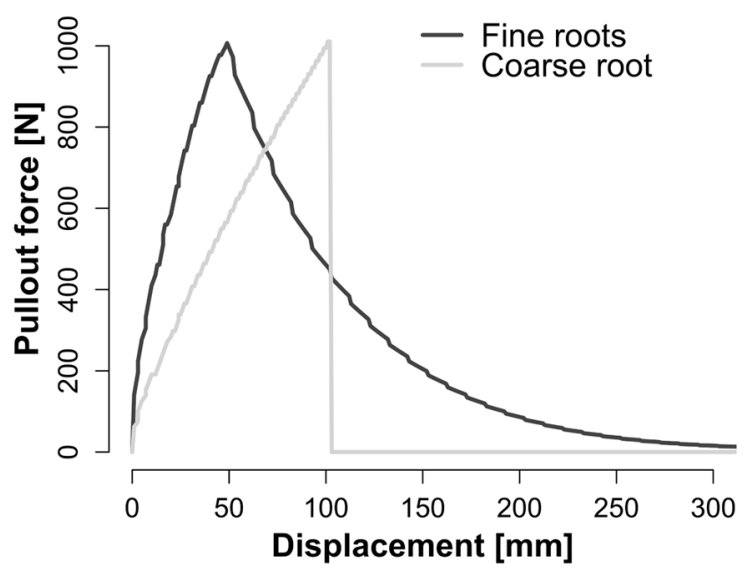

Figure 12. Pullout behaviors for the same maximum pullout force for an individual $20 \mathrm{~mm}$ diameter coarse root and 23 fine roots with diameters of $2 \mathrm{~mm}$. 


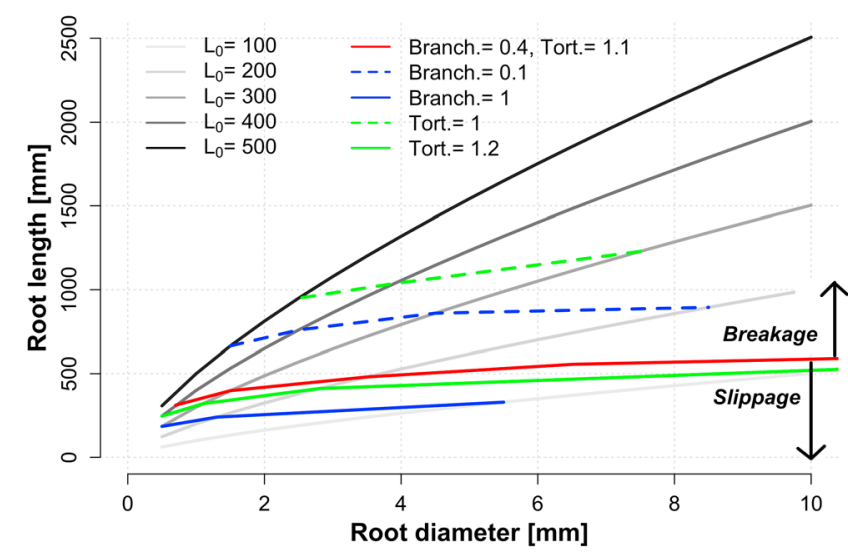

Figure 13. Computed map of breakage versus slippage as a function of root length and root diameter. Colored curves show the transition from slip to failure for different values of root tortuosity and branching point coefficients. Superimposed are lines of length versus diameter for different values of $L_{0}$ (equation (1)). For a branching point coefficient of 0.4 and tortuosity of 1.1 (red curve), all roots break if $L_{0}=500$ while only roots of diameter greater than about $4 \mathrm{~mm}$ break if $L_{0}=200$.

equation (1) with fitted coefficients) the longer root can redistribute forces over greater distances in the soil.

[50] Figure 13 shows the breakage-slippage threshold on a length-diameter plot for different values of branching coefficient and tortuosity. In general, short roots (small values of $L_{0}$ ) with low friction tend to slip, while long roots with high friction almost always break. Results also show that once the values of branching coefficient and tortuosity are fixed the threshold is determined primarily by root length and does not depend on root diameter.

\subsubsection{Effect of Root Size Distributions}

[51] Here we compare the influence of different root distributions on root reinforcement of a bundle of roots using measured root distributions and fitted Weibull distributions. Measured root distributions were obtained at three different distances from root stems $(0.5,1.5$, and $2.5 \mathrm{~m})$ for nine spruce trees (Picea abies L.) in the educational forest of
ETH Zurich (Switzerland) (see Vanomsen [2006] for study area description). Tree stem diameter at $1.3 \mathrm{~m}$ height was in the range of 20 to $30 \mathrm{~cm}$. Trenches $50 \mathrm{~cm}$ deep and $50 \mathrm{~cm}$ wide were dug tangentially to concentric circles around selected trees and the position of the trench was chosen to minimize overlapping root systems with neighboring trees. Figures 14 and 15 show root size data measured in the field and found in the literature [Wu et al., 1988; Zhou et al., 1998] and Weibull fits. We used the relative percentage of distribution of each root diameter class for each distance from tree stem for the fit of the Weibull distribution. The best fit was found for $m=1.2$ and $k=1.9$ using least square error minimization. The variance of the model results is 0.19 with a standard error less than 0.01 . Using the same Weibull function, we fitted the data of $W u$ et al. [1988] and Zhou et al. [1998], obtaining $m=1$ and $k=0.8$ for $\mathrm{Wu}$ et al. and $m=1$ and $k=3.3$ for Zhou et al. (see Figure 15).

[52] Field measured root distribution data exhibit a linear relation between distance from tree stem and the total number of roots present in a soil profile. Figure 16 shows that $(0.5 \mathrm{~m}$ away from the tree stem) there were on average 88 roots per square meter in the top $0.5 \mathrm{~m}$ of soil profile. The extrapolation of the linear regression indicates that, for trees with $20-30 \mathrm{~cm}$ in stem diameter, the maximal rooting distance is about $4.3 \mathrm{~m}$. Such information is important for realistic estimation of root reinforcement at the scale of an individual tree allowing implementation of the RBM at different distances from the tree stem.

[53] Finally, Figure 17 shows how maximal root reinforcement varies with distance from the tree stem for a measured field distribution and its Weibull fit. The Weibull fit underestimates the pullout force particularly close to the tree stem. This is because fitted Weibull distribution results in less coarse roots than measured, which contribute most to root reinforcement.

\section{Discussion}

[54] The proposed modeling approach quantifies the influence of key root parameters on the force at failure of an individual root (see Table 2) and of a bundle of roots during pullout conditions. The model also yields an estimate of the force-displacement behavior of root reinforcement that could be used in soil strength or slope stability calculations.

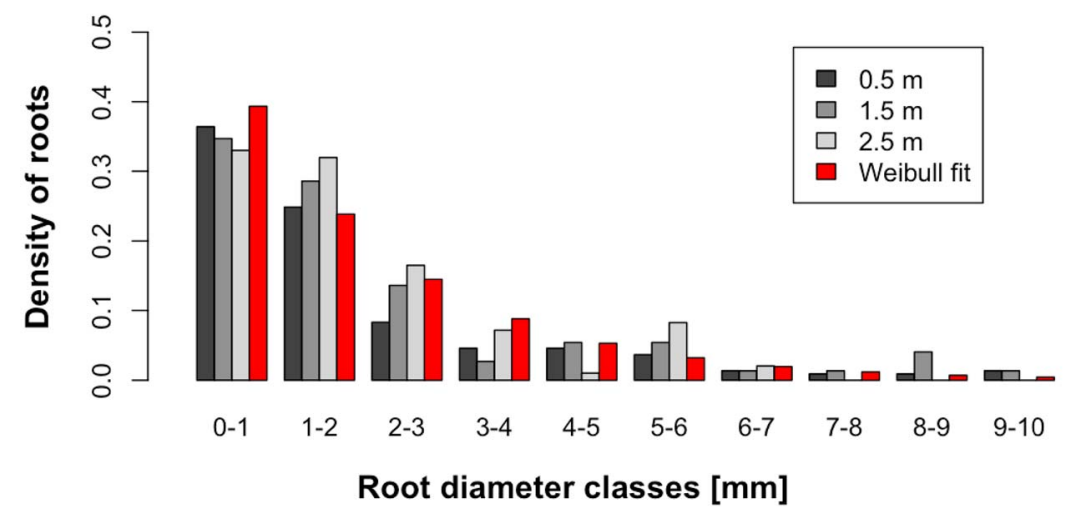

Figure 14. Fitted field data of mean root density distribution for nine spruce trees at three different distances from the stem $(0.5,1.5$, and $2.5 \mathrm{~m})$ using a Weibull probability function. For this fit the SSE is 0.03 . 

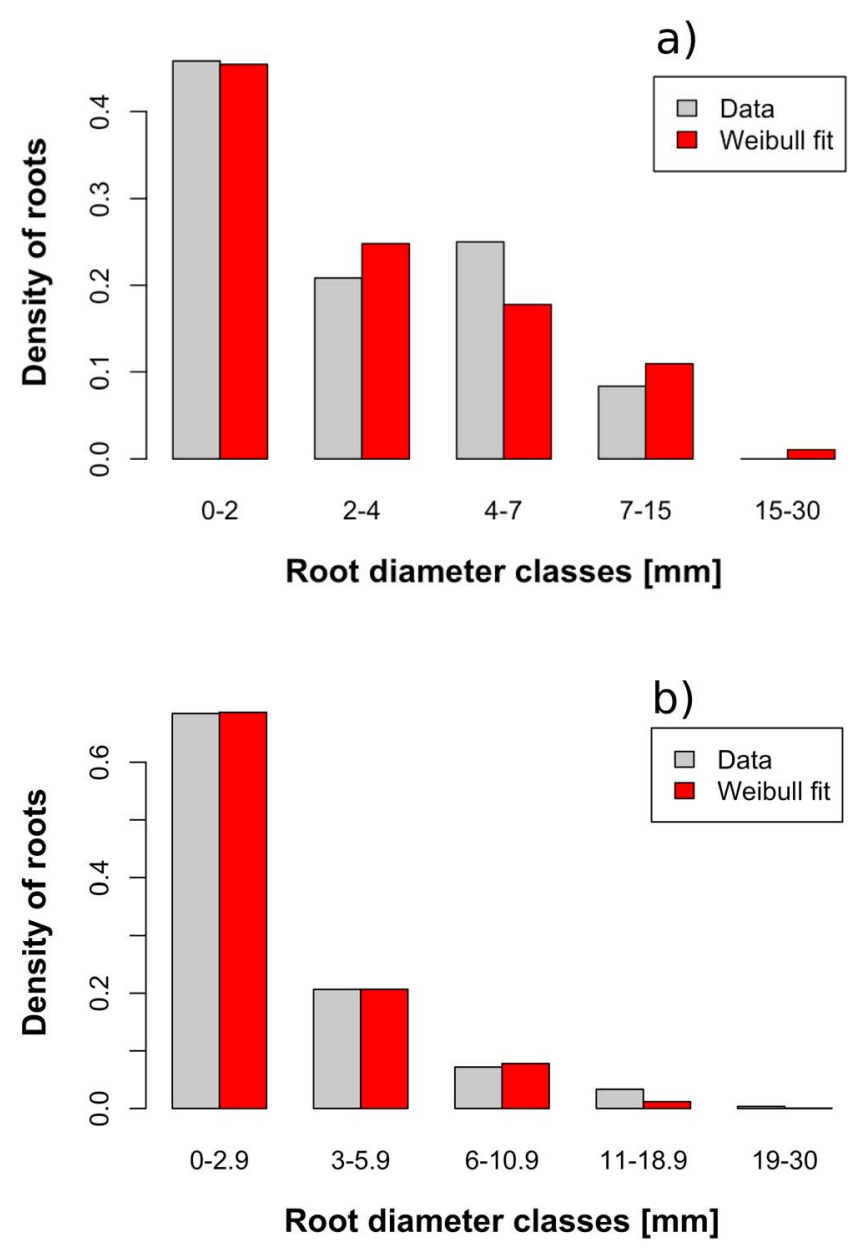

Figure 15. Fitting curves using the Weibull probability function for two data sets found in the literature [ $\mathrm{Wu}$ et al., 1988; Zhou et al., 1998]. (a) The used function parameters are $m=1$ and $k=3.3$ (SSE is 0.0076 ) for the data set of $W u$ et al. [1988] and (b) are $m=1$ and $k=2.5$ (SSE is 0.0005) for the data set of Zhou et al. [1998]. To fit the Weibull model to the literature data we used cumulative values of probability of the root diameter classes as given by the authors. In the case of the data of Wu et al. [1988] the root diameter classes are $0-2,2-4,4-7,7-15$, and 15-30 $\mathrm{mm}$. In the case of the data of Zhou et al. [1998] the classes are 0-1, $1-4,4-8,8-14$, and $14-24 \mathrm{~mm}$.

The innovative elements of this approach are the implementation of natural geometrical factors such as root tortuosity and branching point friction in the analysis of the individual root pullout behavior, the use of an analytical root distribution model, and the use of a fiber bundle model approach to describe the global behavior of a bundle of roots that includes different types of failure mechanisms (stretching, breakage, and slip out), an aspect not considered in other existing models.

\subsection{Individual Root Behavior}

[55] Due to their geometrical and mechanical properties small roots tend to slip out first and then break, while under similar conditions larger roots $(>2 \mathrm{~mm}$ diameter) tend to break without slipping out (Figure 13). One of the important outcomes of the proposed model is an estimation of the displacement at the maximal tensile force, as discussed by Schwarz et al. [2009]. This is particularly important for better understanding how roots contribute to the stabilization of a slope and how they influence the triggering of shallow landslides. Results show that the maximal tensile force of a root is attained at different displacements for different root diameter classes. This result represents a fundamental output needed for the application of the Fiber Bundle Model approach to real roots. The estimation of root length has a major influence on model prediction, as already mentioned by Ennos [1990]. The small number of studies on this topic and the wide range of values this parameter can assume depending on plant species and stand, make estimation of root length quite challenging. Nevertheless, the use of empirical relations calibrated fitted to field or literature data still provide a plausible estimation of root reinforcement. Results show that including variations in root diameter along its length influences failure mechanisms for smallest root diameter classes and the displacement at which maximal pull out force occurs by about $10 \%$. In general, higher friction (due to either more branching points, increased tortuosity, or enhanced root-soil interfacial friction) leads to an increase in both the maximal pullout force and the displacement at maximal pullout force if a root slips out. When the maximal pullout force exceeds root tensile strength, maximal pullout force remains constant (at breakage threshold) and displacement at maximal pullout force decreases. The decrease in displacement at maximal pullout force is due to the reduction in activated root length needed to attain total friction equaling maximal root tensile strength.

[56] The most sensitive geometrical and mechanical parameters are tortuosity and branching point friction coefficient. While mean tortuosity of roots may be quantified in a consistent way with real values ranging from 1.0 to 1.2 , the quantification of branching point friction coefficient is more difficult. Only a few experimental data are reported where attempts to quantify this parameter were made. The work of Stokes et al. [1996], which focused on the influence of insertion angle of lateral root branches on pull out force, showed that for a certain type of branching pattern, a variation of branching angle from $30^{\circ}$ to $90^{\circ}$ increased pullout force for an individual branching point by less then 5\%. Moreover, the numerical simulation of Dupuy et al. [2005] showed that the most plausible variable for estimation of additional friction due to branching point is the diameter of the root's main axis. In addition, Mickovski et al. [2007] showed that, branching point positions (at different confining pressures) influence friction. Parameters such as confining pressure, water content, and root-soil interface friction angle show a maximal influence on the displacement at maximal tensile force of about $10 \%$, while the influence on maximal tensile force was even less pronounced. The nonlinear behaviors of stress-strain curves has also been observed during single-root tensile tests in the laboratory (not embedded in soil) [Commandeur and Pyles, 1991], even if in this case the nonlinearity is less accentuated than when progressively activating roots (such as in a field pullout test). We thus conclude that part of the non- 


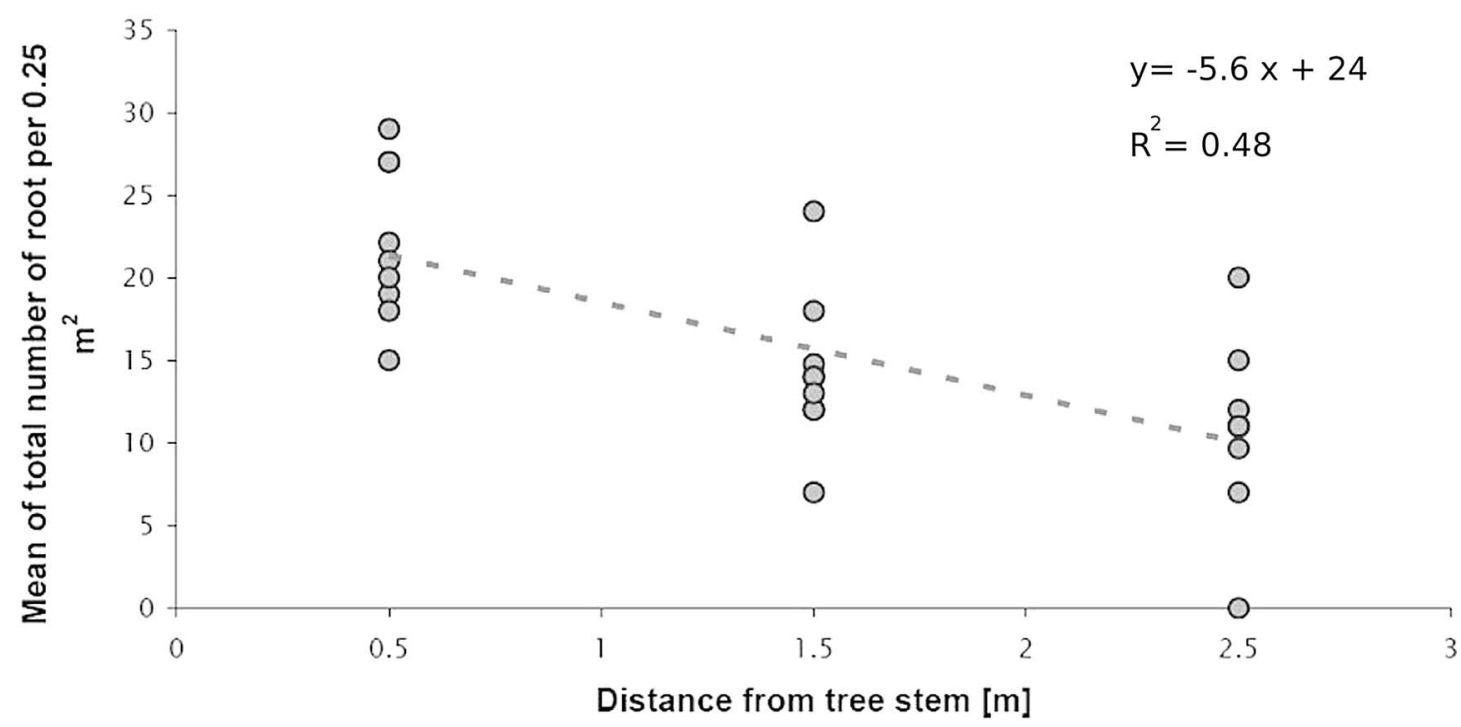

Figure 16. Distribution of the total number of roots at different distances from the tree stem. (Note that some of the nine data sets collected for each distance overlap.)

linearity may be attributed to tortuosity and to redistribution of forces between the fibers within the root material.

\subsection{Slip Out Phase}

[57] The approach used for estimating residual root pullout force during slip out phase is characterized by new and potentially important components. First, we introduced the use of a dynamic friction to estimate root-soil interfacial force distribution. Second, we considered an iterative process for root contraction. Finally, we calculated the variation of root surface area along the root axis based on the variation in root diameter. As shown in Figure 8, these factors influence the estimation of residual root slip out force. An aspect not explicitly implemented in the model is the capacity of the soil to fill the void left behind big root segments or by large branching points. For plastic soils this mechanism will reduce the residual root-soil interfacial friction force to near zero after a few millimeters of displacement. In granular and cohesionless materials, however, the void left behind slipping roots will be filled by soil grains and the residual-dynamic friction strength will remain constant with a nonzero value. These effects are considered in our calculations for empirically calibrated dynamic coefficient $c$ (equation (25)).

[58] Depending on soil type, soil moisture may have important influence on pullout behavior of root bundles. On the one hand, increased matric potential in wet sand will not only increase sand stiffness by increasing effective stress, but would also modify friction and dilation behavior during shearing [Mickovski et al., 2007]. In natural soils, moisture conditions and the structure of the soil also strongly influence the compressibility of the soil [Lang et al., 2003]. Soilmoisture conditions exert a relatively small influence on the behavior of an individual root in comparison to other parameters. Soil moisture influences both the root-soil interfacial friction and the apparent Young's modulus. In contrast, soil moisture plays a major role in the global behavior of a bundle of roots. Considering an individual root, the variations of the maximal pull out force and displacement due to soil moisture are at most $10 \%$. However, even a small variation in soil moisture can lead to a change in the type of failure (slipping instead of breaking). In this case, these relative small variations may lead to big differences in the global pull out behaviors of a bundle of roots, particularly when small roots outnumber coarse roots (as is the case in all real situations). Figure 18 shows how soil moisture influences global pullout behavior of a typical

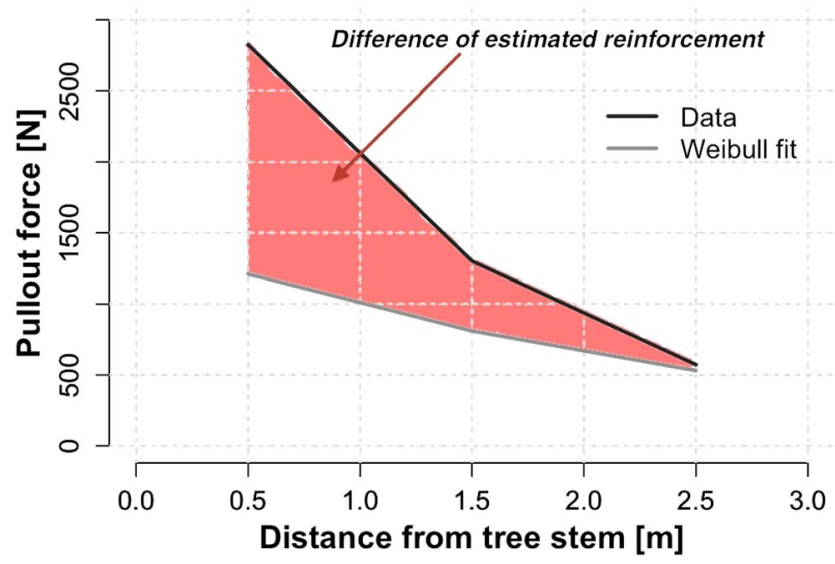

Figure 17. Calculated values of maximal root reinforcement as a function of distance from the tree stem for two series of root distributions. First, we used mean values of root distribution collected in the field (Uetliberg); second, we used the fitted values of root distribution obtained using the Weibull probability function. The considered soil profile was $50 \mathrm{~cm}$ in width and $50 \mathrm{~cm}$ deep. 
Table 2. List of Terms

\begin{tabular}{|c|c|c|c|c|}
\hline Symbol & Unit & Description & Values & Reference \\
\hline$\alpha$ & {$[-]$} & Coeff. equation (8) & Table 1 & Table 1 \\
\hline$\beta$ & {$[-]$} & Coeff. equation (8) & Table 1 & Table 1 \\
\hline$\gamma$ & {$\left[{ }^{\circ}\right]$} & Angle between root sub-segments & 24.6 & Schwarz et al. [2010] \\
\hline$\Delta L_{\text {con }}$ & {$[\mathrm{mm}]$} & Variation of root length due to contraction & equation (32) & - \\
\hline$\Delta L_{\mathrm{em}}$ & {$[\mathrm{mm}]$} & Variation of embedded root length in the soil & equation (31) & - \\
\hline$\Delta x$ & {$[\mathrm{~mm}]$} & Displacement & - & - \\
\hline$\Delta d$ & {$[\mathrm{~mm}]$} & Root radial contraction & $0.1 d$ & - \\
\hline$\varepsilon$ & {$[-]$} & Strain & - & - \\
\hline$\varepsilon_{i}$ & {$[-]$} & Strain of the root segment $i$ & - & - \\
\hline$\varepsilon_{i}^{f}$ & {$[-]$} & Component of strain due to root material $i$ & - & - \\
\hline$\varepsilon_{i}^{\mathrm{t}}$ & {$[-]$} & Component of strain due to root tortuosity $i$ & - & - \\
\hline$\varepsilon_{f}$ & {$[-]$} & Root local strain & - & Naaman et al. [1991] \\
\hline$\varepsilon^{\max }$ & {$[-]$} & Maximal strain of a root & - & - \\
\hline$\varepsilon^{\max }$ & {$[-]$} & Maximal root strain & - & - \\
\hline$\varepsilon^{\text {slip }}$ & {$[-]$} & Root strain due to the slip out friction & - & - \\
\hline$\zeta$ & {$[-]$} & Empirical coeff. & - & - \\
\hline$\theta$ & {$[-]$} & Volumetric water content & - & - \\
\hline$\theta_{\text {sat }}$ & {$[-]$} & Volumetric water content in saturated condition & - & - \\
\hline$\theta_{\min }$ & {$[-]$} & Volumetric water content corresponding to $c_{\max }^{\prime}$ & - & - \\
\hline$\lambda$ & {$[-]$} & Empirical ratio between $E_{\mathrm{t}}$ and $E_{\mathrm{f}}$ & - & Commandeur and Pyles [1991] \\
\hline$\nu_{f}$ & {$[-]$} & Poisson's ratio & 0.3 & Dupuy et al. [2005] \\
\hline$\sigma$ & {$[\mathrm{kPa}]$} & Stress & - & 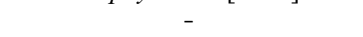 \\
\hline$\sigma^{\prime}$ & {$[\mathrm{Pa}]$} & Effective normal stress & - & Lu and Likos [2006] \\
\hline$\sigma_{\text {tort }}^{\prime}$ & {$[\mathrm{Pa}]$} & Tortuous effective stress & equation (17) & - \\
\hline$\sigma$ & {$[\mathrm{Pa}]$} & Total normal stress & - & - \\
\hline$\tau_{b}$ & {$[\mathrm{~Pa}]$} & Bonded friction & equation (13) & Naaman et al. [1991] \\
\hline$\tau_{d}$ & {$[\mathrm{~Pa}]$} & Debonded friction & equation (16) & - \\
\hline$\tau_{\text {dyn }}$ & {$[\mathrm{Pa}]$} & Root dynamic friction & equation (25) & Cuhna et al. [2008] \\
\hline$\phi$ & {$\left[{ }^{\circ}\right]$} & Residual root-soil friction angle & 35 & - \\
\hline$\chi$ & {$[-]$} & Effective stress parameter & - & Lu and Likos [2006] \\
\hline$A_{i}$ & {$\left[\mathrm{~mm}^{2}\right]$} & Cross-sectional area of root segment $i$ & - & $-n^{2}-1$ \\
\hline$A_{0}$ & {$\left[\mathrm{~mm}^{2}\right]$} & Cross-sectional area of root segment 0 & $\pi / 4$ & - \\
\hline$A_{n}$ & {$\left[\mathrm{~mm}^{2}\right]$} & Maximal cross-sectional area of root & - & - \\
\hline$B$ & {$[\mathrm{~mm}]$} & Mean branching distance & $10-170$ & - \\
\hline$c$ & {$[-]$} & Empirical coeff. & - & - \\
\hline$c^{\prime}$ & {$[\mathrm{Pa}]$} & Apparent cohesion & equation (23) and (24) & Lu and Likos [2006] \\
\hline$c_{\max }^{\prime}$ & {$[\mathrm{Pa}]$} & Maximum value of apparent cohesion in unsaturated conditions & $1-510^{3}$ & Goulding [2006] \\
\hline$c_{\text {res }}^{\prime}$ & {$[\mathrm{Pa}]$} & Residual value of apparent cohesion in dry conditions & - & - \\
\hline$d$ & {$[\mathrm{~mm}]$} & Root diameter & $>1$ & Santantonio [1990] \\
\hline$d_{0}$ & {$[\mathrm{~mm}]$} & Diameter of root tip & 1 & Santantonio [1990] \\
\hline$d_{i}$ & {$[\mathrm{~mm}]$} & Diameter of root segment $i$ & - & $-n^{2}-1$ \\
\hline$D$ & {$[\mathrm{~mm}]$} & Straight root length & equation (7) & Schwarz et al. [2010] \\
\hline$D_{0}$ & {$[\mathrm{~mm}]$} & Initial straight root length & equation (10) & Schwarz et al. [2010] \\
\hline$E_{f}$ & [MPa] & Young's modulus root material & equation (9) & Schwarz et al. $[2010]$ \\
\hline$E_{t}$ & {$[\mathrm{MPa}]$} & Young’s modulus of tortuous root & - & Commandeur and Pyles [1991] \\
\hline$E_{\text {app }}$ & {$[\mathrm{MPa}]$} & Apparent Young's modulus of the root & equation (10) & Commandeur and Pyles [1991] \\
\hline$E_{m}$ & {$[\mathrm{MPa}]$} & Young's modulus of soil matrix & - & - \\
\hline$F$ & {$[\mathrm{~N}]$} & Pullout force applied to the root & - & - \\
\hline$F^{\text {if }}$ & {$[N]$} & Maximum pullout force of a root due to interfacial friction & equation (18) & - \\
\hline$F_{\max }^{\mathrm{tot}}$ & {$[N]$} & Total maximal friction of a root & equation (30) & - \\
\hline$f_{i}^{\text {tit }}$ & {$[\mathrm{N}]$} & Total pullout force transmitted to root segment $i$ & equation (28) & - \\
\hline$f_{i}$ & {$[\mathrm{~N}]$} & Pullout friction due to root segment $i$ & equation (27) & - \\
\hline$f_{i}^{b p}$ & {$[N]$} & Branching point friction & equation (26) & - \\
\hline$i$ & {$[-]$} & Root segment index & - & - \\
\hline $\mathrm{k}$ & {$\left[\mathrm{Pa} / \mathrm{m}^{2}\right]$} & Bond modulus & $10^{9}$ & - \\
\hline$k$ & [] & Scale parameter of the Weibull distribution & $0.8-3.3$ & - \\
\hline$L$ & {$[\mathrm{~mm}]$} & Tortuous root length & equation (1) & Commandeur and Pyles [1991] \\
\hline$l$ & {$[\mathrm{~mm}]$} & Tortuous length along root & - & - \\
\hline$L_{0}$ & {$[-]$} & Coeff. eq. root length & $100-500$ & Pollen et al. [2004] \\
\hline$L_{e}$ & {$[-]$} & Exponent eq. root length & 0.7 & Pollen et al. [2004] \\
\hline$L_{\text {slip }}$ & {$[\mathrm{mm}]$} & Root length embedded in the soil during slippage & equation (33) & - \\
\hline$m$ & {$[-]$} & Shape parameter of the Weibull distribution & $1-1.2$ & - \\
\hline$N$ & {$[-]$} & Number of root diameter classes & - & Schwarz et al. [2010] \\
\hline$n$ & {$[-]$} & Number of branching points & equation (2) & $-n^{2}-1$ \\
\hline $\mathrm{S}$ & {$[\mathrm{m}]$} & Local root-soil interface slip & $10^{-5}$ & - \\
\hline$s$ & {$[-]$} & Scaling factor & 0.75 & Collet et al. [2006] \\
\hline$T^{\max }$ & {$[\mathrm{MPa}]$} & Maximum tensile strength & equation (8) & - \\
\hline$u_{a}$ & {$[\mathrm{~Pa}]$} & Pore air pressure & 0 & - \\
\hline$u_{w}$ & {$[\mathrm{~Pa}]$} & Pore air pressure & 0 & - \\
\hline $\mathrm{Y}$ & {$[\mathrm{N} / \mathrm{m}]$} & Empirical branching coeff. & $0-1$ & Schwarz et al. [2010] \\
\hline$z$ & {$[-]$} & Root tortuosity & 1.1 & Schwarz et al. [2010] \\
\hline
\end{tabular}




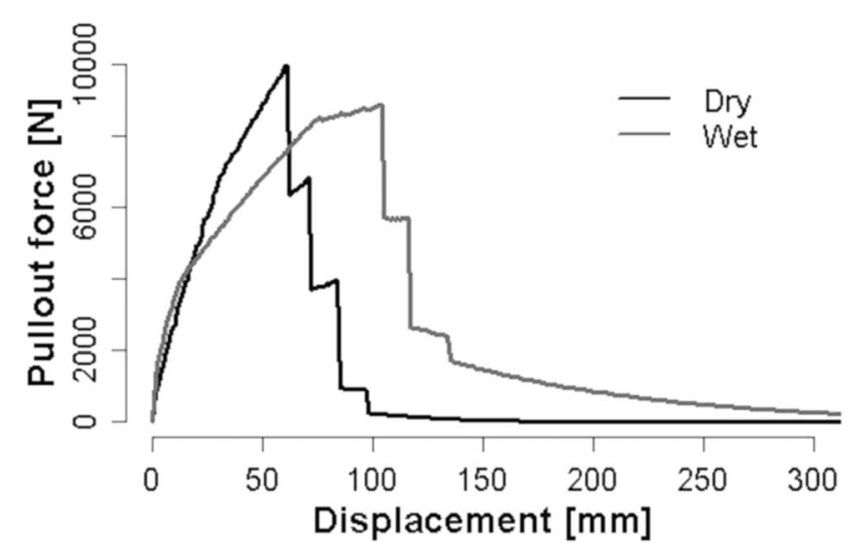

Figure 18. Modeled results of root reinforcement behavior for two different soil moisture conditions ( $20 \%$ degree of saturation for dry and $90 \%$ degree of saturation for wet), based on the root distribution data of Zhou et al. [1998].

bundle of spruce roots. Generally speaking, roots in wet soil ( $60 \%$ to $100 \%$ degree of saturation) show a smaller resistance to pullout and a higher displacement at maximal pullout force. However, the effect of soil moisture on the global behavior of a bundle is strongly influenced by root size distribution: it is possible that the maximal pullout resistance is higher in wet soil than in dry soil because of the residual strength of small roots.

\subsection{Root Bundle Model}

[59] One of the interesting results of the application of the RBM is the confirmation that maximal pullout force of different root diameters takes place at different displacements, illustrating the shortcomings of one of the key assumptions in Wu et al.'s [1979] model. Furthermore, the RBM allows estimation of mean displacement value at maximal pullout force for different root diameter classes. The result highlights the importance of considering root diameter distribution (for a single root as well as at the stand level) and shows that the use of Wu et al.'s [1979] model, even for relative comparison, may produce large errors due to the different root distributions [De Beats et al., 2008]. In this study, the choice of the Weibull distribution to fit root distribution data is justified on the basis of its mathematical flexibility and its superior performance in estimation of the number of large roots when compared with a lognormal distribution. Large roots have more influence on the global behavior of a root bundle and thus estimating their numbers is critical. The range of Wu's model overestimation is strongly dependent on details of root distribution. Assuming a unique value of maximal root strength, Young's modulus, and root length for each root diameter class still leads to an overestimation (see Figure 19). The theory behind the FBM [Sornette, 1989] shows that the variability of these values leads to a lower global maximal strength of the fiber bundle.

[60] In the FBM extension proposed in this work, we assumed that no interactions take place between roots of the same bundle. In reality this may be true only if roots are sufficiently far away from each other. Overlapping and interconnections between roots would lead to a more com- plex mechanism of force redistribution and to a different stress-strain behavior for the bundle. Data indicate that the mean interdistance of roots ranges between one root every 0.1 to $0.3 \mathrm{~m}$ [Zhou et al., 1998; Wu et al., 1988]. Some studies indicate also that fine roots tend to be clustered [Achat et al., 2008], which means that irrespective of their density, roots would be interacting. Considering that at a certain distance from tree stems, the density of roots decreases exponentially [Ammer and Wagner, 2005], it is reasonable to neglect root interactions in slopes with sparse vegetation. Moreover, field observations and results of numerical simulations show that fine roots play in many cases a central role in slope stabilization. There are two reasons for these conclusions: first, fine roots maximal strength is activated at small displacements suppressing even the smallest of deformations before the system acquires significant kinetic energy, and second, fine roots are more numerous and their distribution on the slope more homogeneous than the distribution of coarse roots. In situations where the growth of lateral coarse root networks can be achieved, slope stabilization will be assured through maximal root reinforcement of coarse roots and through an efficient horizontal redistribution of forces. As showed by Zhou et al. [1998] lateral root reinforcement is displacement-dependent, and our numerical simulations show that force-displacement behaviors of a root bundle are strongly dependent on root diameter distribution (Figure 19). Therefore, future implementation of root reinforcement in slope stability calculations must consider this aspect, either in an infinite slope approach or in detailed numerical models.

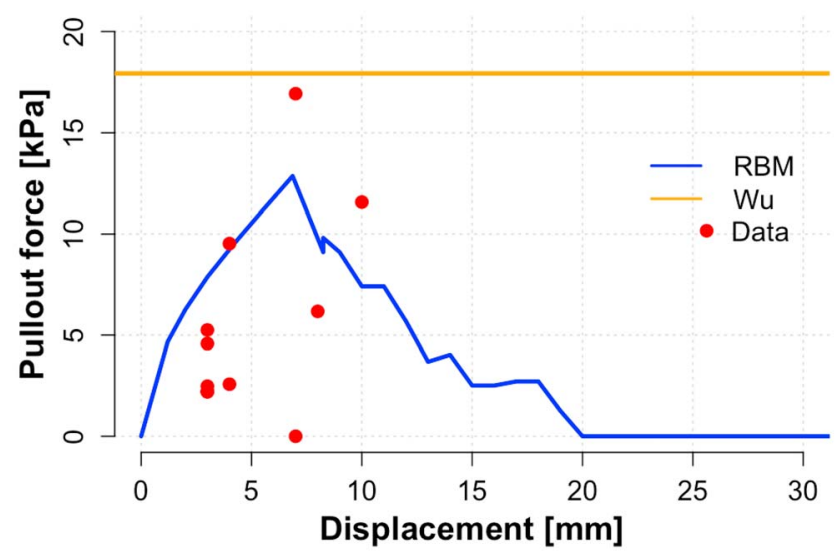

Figure 19. Modeled behavior of root reinforcement for the data of Zhou et al. [1998] for $1 \mathrm{~m}^{2}$ soil profile fitting the mean root distribution with the Weibull distribution function. The calculated maximal reinforcement using the $\mathrm{Wu}$ model [Wu et al., 1979] was $18 \mathrm{kPa}$, while the maximal pullout force predicted with the RBM was about $13 \mathrm{kPa}$, which is closer to the measured values $(0.22-16.9 \mathrm{kPa})$. It is important to consider that no root distributions of the single data are reported, and thus, just the mean distribution was used for the root reinforcement estimation [see Zhou et al., 1998, Table 2]. For the input values of the model we used mean values showed in the methods (branching coefficient is 0.4 and tortuosity is 1.1 ). 


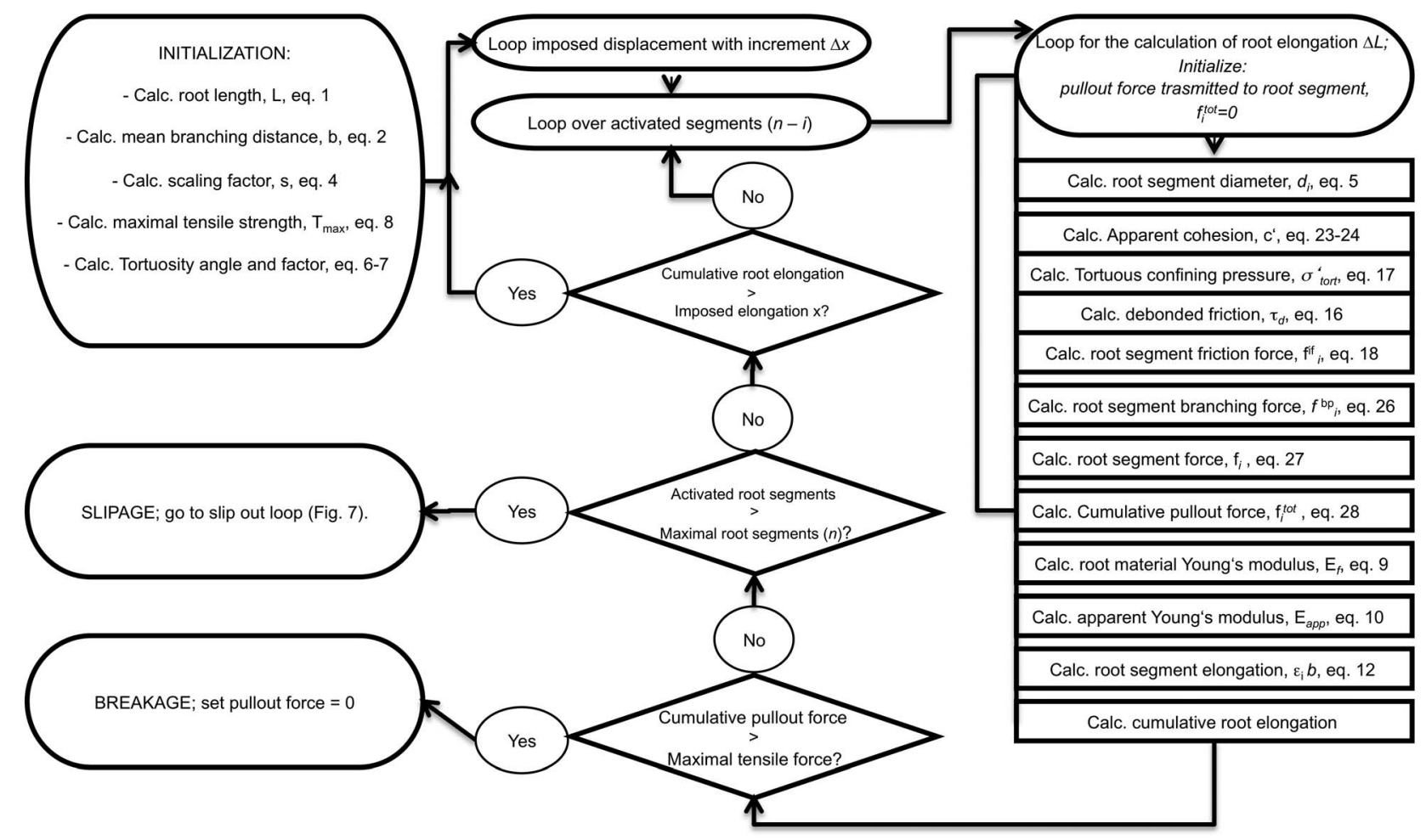

Figure A1. Flowchart of the model use to calculate the pullout force in the stretching and breakage phases of the force-displacement behavior of an individual root.

\subsection{RBM and Slope Stability}

[61] Schwarz et al. [2009] highlighted the importance of the force-displacement relations for realistic implementations of root reinforcement in slope stability calculations. Results of our model show that the implementation of vegetation mechanical effects in slope stability calculation must take into account two important aspects. First, not all roots break simultaneously and thus the RBM approach allows a more realistic estimation of root reinforcement. Second, not all resisting forces on a slope act at the same time or amount of displacement. Hence, maximal lateral soil cohesion should not be added to the maximal lateral root reinforcement, because they reach their maximal values at different displacements [Schwarz et al., 2009]. By analogy, root reinforcement at the basal slip surface should be added to the residual shear strength of the soil material and not to the maximal value [Lang et al., 2003]. Moreover, with simple parameterization the model allows estimation of root reinforcement at a high spatial resolution [Schwarz et al., 2009, 2010], and not at only at an average and uniform stand scale values as usually done. In addition, the implementation of the RBM in slope stability model permits a better estimation of the volume of shallow landslides because the information on the force-displacement behavior of the rooted soil allows the simulation of crack propagation during failure. The possibility to better estimate the volume of shallow landslides is an important information for the modeling of sediment transport in a catchment [Bathurst et al., 2007] and debris flow simulations [Christen et al., 2007]. The results of this work and other studies [Casadei and Dietrich, 2003; Schwarz et al., 2009], lead to a more general discussion on the role of vegetation in mitigating slope instabilities. Considering mechanical aspects only, one can conclude that even shallow rooted slopes may be stabilized by root networks but the effective contribution of a root network to slope stability is strongly dependent on plant distribution, slope steepness, and the hydromechanical properties of soil material.

\section{Conclusions}

[62] In summary, we have presented a model for the estimation of root reinforcement which captures the mechanical behavior of root-soil interactions more realistically and yields force-displacement pullout behavior of a root bundle. Model estimates of tensile strength rely on the following characteristic elements: (1) variations of Young's modulus as a function of root diameter along each root, (2) consideration of root tortuosity and compression properties of the soil, (3) consideration of root deformations, (4) inclusion of branching points as single friction element, (5) incorporating of static and dynamic root-soil friction, (6) consideration of root-soil friction variation as a function of soil water content and soil type, and (7) accounting for the progressive root-soil friction activation. This study highlights the role of root bundle composition (size and geometry) on macroscopic mechanical behavior of root bundles. The quantification of the stress-strain behavior of a bundle of roots leads to new insights regarding the role of root reinforcement in slope stability. The results show that the 
overestimation of root reinforcement using $W u$ et al.'s [1979] approach ranges from 0 to $90 \%$. The consideration of force-displacement behaviors, as done in the RBM, highlight how the overestimation due to $\mathrm{Wu}$ et al.'s approach strongly depends on root size distribution. Moreover, the sensitivity analysis of the model highlights key topics for further research. These topics include: the need for more quantitative methods for the estimation of root distribution and root geometrical parameters (like root length, root tortuosity, and branching patterns), the use of probability density functions to describe the variability of the mechanical parameters of roots, implementation of these probability functions in a system of equations to obtain a mathematical description of the root bundle mechanical behavior, and finally, a better understanding of how roots contribute in space and time to the force redistribution on a vegetated slope.

\section{Appendix A: Algorithm}

[63] Figure A1 illustrates the algorithm used for calculating stretching and breakage phases of the force-displacement behavior of an individual root. The equations used in the different steps of the algorithm are reported in detail and referenced in the text in order to facilitate understanding of the major steps in the root-soil mechanical model.

[64] Acknowledgments. This work was supported by the CCES platform (Competence Center for Environmental Sustainability) of the ETH domain and is part of the TRAMM project (Triggering of Rapid Mass Movement). We thank Fabian Rüdy for illustrations and Christof Hofer for helpful discussions.

\section{References}

Abe, K., and R. R. Ziemer (1991), Effects of tree roots on a shear zone: Modelling reinforced shear stress, Can. J. For. Res., 21, 1012-1019.

Abernethy, B., and A. I. Rutherfurd (2001) The distribution and strength of riparian tree roots in relation to riverbank reinforcement, Hydrol. Processes, 15, 63-79.

Achat, D. L., M. R. Bakker, and P. Trichet (2008), Rooting patterns and fine root biomass of Pinus pinaster assessed by trench wall and core methods, J. For. Res., 13, 165-175.

Ammer, C., and S. Wagner (2005), An approach for modelling the mean fine-root biomass of Norway spruce stands, Trees, 19, 145-153.

Bathurst, J. C., G. Moretti, A. El-Hames, S. Begueria, and J. M. GarciaRuiz (2007), Modelling the impact of forest loss on shallow landslide sediment yield, Ijuez river catchment, Spanish Pyrenees, Hydrol. Earth Syst. Sci., 11, 569-583.

Bischetti, G. B., E. A. Chiaradia, T. Limonato, B. Speziali, B. Vitali, P. Vullo, and A. Zocco (2005), Root strength and root area ratio of forest species in Lombardy (Northern Italy), Plant Soil, 278, 11-22.

Casadei, M., and W. E. Dietrich (2003), Controls on shallow landslide width, in Debris-Flow Hazards Mitigation: Mechanics, Prediction, and Assessment, pp. 91-102, Millpress, Rotterdam, Netherlands.

Christen, M., P. Bartelt, and U. Gruber (2007), RAMMS: A modeling system for snow avalanches, debris flows and rockfalls based on IDL, Photogram. Fernerkundung Geoinf., 4, 289-292.

Collet, C., M. Löf, and L. Pagès (2006), Root system development of oak seedlings analysed using an architectural model: Effects of competition with grass, Plant Soil, 279, 367-383.

Commandeur, P. R., and M. R. Pyles (1991), Modulus of elasticity and tensile strength of Douglas-fir roots, Can. J. For. Res., 21, 48-52.

Coutts, M. P. (1983), Root architecture and tree stability, Plant Soil, 71, 171-188.

Cuhna, V. M. C. F., J. A. O. Barros, and J. M. Sena-Cruz (2008), Bond-slip mechanisms of hooked-end steel fibers in self-compacting concrete, Mater. Sci. Forum, 587-588, 877-881.

Danjon, F., and B. Reubens (2008), Assessing and analyzing 3D architecture of woody root systems, a review of methods and applications in tree and soil stability, resource acquisition and allocation, Plant Soil, 303, 1-34, doi:10.1007/s11104-007-9470-7.
De Beats, S., J. Poesen, B. Reubens, K. Wemans, J. De Baerdemaeker, and B. Muys (2008), Root tensile strength and root distribution of typical Mediterranean plant species and their contribution to soil shear strength, Plant Soil, 305, 207-226.

Dupuy, L., T. Fourcaud, and A. Stokes (2005), A numerical investigation into factors affecting the anchorage of roots in tension, Eur. J. Soil Sci., 56, 319-327.

Ekanayake, J. C., and C. J. Phillips (1999), A method for stability analysis of vegetated hillslopes: An energy approach, Can. Geotech. J., 36, $1172-1184$

Ennos, A. R. (1990), The anchorage of leek seedlings: The effect of root length and soil strength, Ann. Bot., 65, 409-416.

Fan, C. C., and C. F. Su (2008), Role of roots in the shear strength of rootreinforced soils with high moisture content, Ecol. Eng., 33, 157-166.

Genet, M., N. Kokutse, A. Stokes, T. Fourcaud, X. Cai, J. Ji, and S. B. Mickovski (2008), Root reinforcement in plantation of Cryptomeria japonica D. Don: Effect of tree age and stand structure on slope stability, For. Ecol. Manage., 256, 1517-1526.

Ghezzehei, T. A., and D. Or (2000), Dynamics of soil aggregate coalescence governed by capillary and rheological processes, Water Resour. Res., 36, 367-379.

Goulding, R. B. (2006), Tensile strength, shear strength, and effective stress for unsaturated sand, Ph.D. dissertation, Univ. of Mo., Columbia.

Hallett, P. D., K. W. Loades, S. B. Mockovski, A. G. Bengough, M. F. Bransby, M. C. R. Davies, and R. Sonnenberg (2009), An assessment of models that predict soil reinforcement by plant roots, Geophys. Res. Abstr., 11, EGU2009-8925.

Hamza, O., A. G. Bengough, M. F. Bransby, M. C. R. Davies, and P. D. Hallett (2007), Mechanics of root-pullout from soil: A novel image and stress analysis procedure, in Eco-and Ground Bio-Engineering: The Use of Vegetation to Improve Slope Stability, edited by A. Stokes et al., pp. 213-221, Springer, Dordrecht, Netherlands.

Johnsson, M., A. Foetzki, M. Kalberer, T. Lundström, W. Amman, and V. Stöckli (2006), Root-soil rotation stiffness of Norway spruce (Picea abies (L.) Karst) growing in subalpine forested slopes, Plant and Soil, 285, 267-277.

Lang, H. J., J. Huder, and P. Amann (2003), Bodenmechanik und Grundbau, 7th ed., 317 pp., Springer, Berlin.

Li, J. X. (1994), Analysis of the pullout of single fibers from low-density polyethylene, J. Appl. Polym. Sci., 53, 225-237.

Lu, N., and W. J. Likos (2006), Suction stress characteristic curve for unsaturated soil, J. Geotech. Geoenviron. Eng., 132, 131-142.

Mickovski, S. B., A. G. Bengough, M. F. Bransby, M. R. C. Davies, P. D. Hallet, and R. Sonnenberg (2007), Material stiffness, branching pattern and soil matric potential affect the pullout resistance of model root systems, Eur. J. Soil Sci., 58, 1471-1481.

Mickovski, S. B., P. D. Hallett, M. F. Bransby, M. C. R. Davies, R. Sonnenberg, and A. G. Bengough (2009), Mechanical reinforcement of soil by willow roots: Impacts of root properties and root failure mechanism, Soil Sci. Soc. Am. J., 73, 1276-1285, doi:10.2136/sssaj2008.0172. Moroni, M. T., D. Worledge, and C. L. Beadle (2003), Root distribution of Eucalyptus nitens and E. globules in irrigated and droughted soil, For. Ecol. Manage., 177, 399-407.

Naaman, A. E., G. G. Namur, J. M. Alwan, and H. S. Najm (1991), Fiber pullout and bond slip. I: Analytical study, J. Struct. Eng., 117(9), 2769-2790.

Norris, J. N. (2005), Root reinforcement by hawthorn and oak roots on a highway cut-slope in southern England, Plant Soil, 278, 43-53, doi:10.1007/s11104-005-1301-0.

Nuth, M., and L. Laloui (2008), Effective stress concept in unsaturated soils: Clarification and validation of an unified framework, Int. J. Numer. Anal. Methods Geomech., 32, 771-801.

Operstein, V., and S. Frydman (2000), The influence of vegetation on soil strength, Ground Improv., 4, 81-89.

Ozier-Lafontaine, H., F. Lecompte, and J. F. Sillon (1999). Fractal analysis of the root achitecture of Gliricidia sepium for the spatial prediction of root branching, size and mass: Model development and evaluation in agroforestry, Plant Soil, 209, 167-180.

Pollen, N. (2008), Temporal and spatial variability of root reinforcement in stream banks: Accounting for soil shear strength and moisture, Catena, 69, 197-205.

Pollen, N., and A. Simon (2005), Estimating the mechanical effects of riparian vegetation on stream bank stability using a fiber bundle model, Water Resour. Res., 41, W07025, doi:10.1029/2004WR003801.

Pollen, N., A. Simon, and A. Collison (2004), Advances in assessing the mechanical and hydrologic effects of riparian vegetation on stream bank stability, in Riparian Vegetation and Fluvial Geomorphology, Water Sci. Appl. Ser., vol. 8, edited by S. J. Bennett and A. Simon, pp. 125-139, AGU, Washington, D. C. 
Reubens, B., J. Poesen, F. Danjon, G. Geudens, and B. Muys (2007), The role of fine and coarse roots in shallow slope stability and soil erosion control with a focus on root system architecture: A review, Trees, 21 , 385-402.

Rickli, C. (2001), Vegetationswirkungen und Rutschungen-Untersuchung zum Einfluss der Vegetation auf oberflchennahe Rutschprozesse anhand der Unwetterereignisse in Sachseln OW am 15 August 1997, 97 pp., Eidg. Forsch. WSL, Bundesamt für Umwelt, Wald und Landschaft, Bern. Sanborn, S. E., and J. H. Prévost (2008), Discrete modeling of crack bridging by a discontinuous platelet with a controlled interface, Int. J. Solids Struct., 45, 5059-5073.

Santantonio, D. (1990), Modeling growth and production of tree roots, in Process Modeling of Forest Growth Responses to Environmental Stress, edited by R. K. Dixon et al., pp. 124-135, Timber Press, Portland, Oreg. Schmidt, K. M., J. J. Roering, J. D. Stock, W. E. Dietrich, D. R. Montgomery, and T. Schaub (2001), The variability of root cohesion as an influence on shallow landslide susceptibility in the Oregon Coast Range, Can. Geotech. J., 38, 995-1024.

Schwarz, M., F. Preti, F. Giadrossich, P. Lehmann, and D. Or (2009), Quantifying the role of vegetation in slope stability: A case study in Tuscany (Italy), Ecol. Eng., 36, 285-291, doi:10.1016/j.ecoleng.2009. 06.014 .

Schwarz, M., P. Lehmann, and D. Or (2010), Quantifying lateral root reinforcement in steep slopes-From a bundle of roots to tree stands, Earth Surf. Processes Landforms, 35, 354-367, doi:10.1002/esp.1927.

Sornette, D. (1989), Elasticity and failure of a set of elements loaded in parallel, J. Phys. A Math. Gen., 22, L243-L250.

Stokes, A., J. Ball, A. H. Fitter, P. Brain, and M. P. Coutts (1996), An experimental investigation of the resistance of model root systems to uprooting, Ann. Bot., 78, 415-421.

Tosi, M. (2007), Root tensile strength relationships and their slope stability implications of three shrubs species in the Northern Apennines (Italy), Geomorphology, 87, 268-283.
Van Noordwijk, M., L. Y. Spek, and P. de Willigen (1994), Proximal root diameter as predictor of total root size for fractal branching models, Plant Soil, 164, 107-117.

Vanomsen, P. (2006), Der Einfluss der Durchforstung auf die Verankerung der Fichte hinsichtlich ihrer Sturmresistenz, Ph.D. dissertation, 246 pp., ETH Zurich, Zurich, Switzerland.

Vercambre, G., L. Pages, C. Doussan, and R. Habib (2003), Architectural analysis and synthesis of plum tree root system in an orchard using a quantitative modelling approach, Plant Soil, 251, 1-11.

Waldron, L. J., and S. Dakessian (1981), Soil reinforcement by roots: Calculation of increased soil shear resistance from root properties, Soil Sci., 132, 427-435.

Wu, T. H. (2007), Root reinforcement: Analyses and experiments, in Eco-and Ground Bio-Engineering: The Use of Vegetation to Improve Slope Stability, edited by A. Stokes et al., pp. 21-30, Springer, Dordrecht, Netherlands.

Wu, T. H., W. P. McKinnell, and D. N. Swanston (1979), Strength of tree roots and landslides on Prince of Wales Island, Alaska, Can. Geotech. J., 16, 19-33.

Wu, T. H., P. D. Bettadapura, and E. P. Beal (1988), A statistical model of root geometry, For. Sci., 34, 980-997.

Zhou, Y., D. Watts, Y. Li, and X. Cheng (1998), A case study of effect of lateral roots of Pinus yunnanensis on shallow soil reinforcement, For. Ecol. Manage., 103, 107-120.

D. Cohen and D. Or, Soil and Terrestrial Environmental Physics, Institute of Terrestrial Ecosystems, ETH Zurich, Universitätstrasse 16, CH-8092 Zurich, Switzerland. (denis.cohen@env.ethz.ch; dani.or@env.ethz.ch)

M. Schwarz, Swiss Federal Institute for Forest, Snow and Landscape Research, Zürcherstrasse 111, CH-8903 Birmensdorf, Switzerland. (massimiliano.schwarz@wsl.ch) 